\title{
Safety perspectives on presently considered drugs for the treatment of COVID-19
}

\author{
Sophie Penman ${ }^{1}$, Robyn Kiy ${ }^{1}$, Rebecca Jensen ${ }^{1}$, Christopher Beoku-Betts ${ }^{1}$, Ana Alfirevic ${ }^{1}$, \\ David Back ${ }^{1}$, Saye Khoo ${ }^{1}$, Andrew Owen ${ }^{1}$, Munir Pirmohamed ${ }^{1}$, Kevin Park ${ }^{1}$, Xiaoli \\ Meng $^{1}$, Christopher Goldring ${ }^{1}$, and Amy Chadwick ${ }^{1}$ \\ ${ }^{1}$ University of Liverpool
}

June 15, 2020

\begin{abstract}
Intense effort is underway to evaluate potential therapeutic agents for the treatment of COVID-19. In order to respond quickly to the crisis, the repurposing of existing drugs is the primary pharmacological strategy. Despite the urgent clinical need for these therapies, it is imperative to consider potential safety issues. This is important due to the harm-benefit ratios that may be encountered when treating COVID-19, which can depend on the stage of the disease, when therapy is administered and underlying clinical factors in individual patients. Treatments are currently being trialled for a range of scenarios from prophylaxis (where benefit must greatly exceed risk) to severe life-threatening disease (where a degree of potential risk may be tolerated if it is exceeded by the potential benefit). In this perspective, we have reviewed some of the most widely-researched repurposed agents in order to identify potential safety considerations using existing information in the context of COVID-19.
\end{abstract}

Safety perspectives on presently considered drugs for the treatment of COVID-19.

Sophie L. Penman ${ }^{a *}$, Robyn T. Kiy ${ }^{a *}$, Rebecca L. Jensen ${ }^{a *}$, Christopher Beoku-Betts ${ }^{\mathrm{b}}$, Ana Alfirevic ${ }^{\mathrm{a}}$, David Back ${ }^{\mathrm{a}}$, Saye H. Khoo ${ }^{\mathrm{a}}$, Andrew Owen ${ }^{\mathrm{a}}$, Munir Pirmohamed ${ }^{\mathrm{a}}$, B. Kevin Park ${ }^{\mathrm{a}}$, Xiaoli Meng ${ }^{\mathrm{a} \#}$, Christopher E. Goldringa\#, Amy E. Chadwick ${ }^{\mathrm{a} \#}$

${ }^{a}$ MRC Centre for Drug Safety Science, Department of Pharmacology and Therapeutics, University of Liverpool, Liverpool, L69 3GE, UK

b School of Medicine, University of Liverpool, L69 3GE, UK

Brief abstract

Intense effort is underway to evaluate potential therapeutic agents for the treatment of COVID-19. In order to respond quickly to the crisis, the repurposing of existing drugs is the primary pharmacological strategy. Despite the urgent clinical need for these therapies, it is imperative to consider potential safety issues. This is important due to the harm-benefit ratios that may be encountered when treating COVID-19, which can depend on the stage of the disease, when therapy is administered and underlying clinical factors in individual patients. Treatments are currently being trialled for a range of scenarios from prophylaxis (where benefit must greatly exceed risk) to severe life-threatening disease (where a degree of potential risk may be tolerated if it is exceeded by the potential benefit). In this perspective, we have reviewed some of the most widelyresearched repurposed agents in order to identify potential safety considerations using existing information in the context of COVID-19.

Key words

COVID-19, drug safety, toxicology, drug repurposing 


\section{Abbreviations}

Absolute neutrophil count (ANC), adverse drug reaction (ADR), adverse events (AEs), alanine aminotransferase (ALT), angiotensin receptor blocker (ARB), antibody-dependent enhancement (ADE), AP2-associated protein kinase 1 (AAK1), antigen-dependent enhancement (ADE), aspartate transaminase (AST), chronic obstructive pulmonary disease (COPD), cluster of differentiation 73 (CD73), cytochrome P450 (CYP), deep vein thrombosis (DVT), disease-modifying anti-rheumatic drug (DMARD), drug-drug interaction (DDI), drug-induced liver injury (DILI), Early Access to Medicines Scheme (EAMS), exoribonuclease (ExoN), favipiravir-ribofuranosyl-5'-triphosphate (favipiravir-RTP), human coronavirus (HCoV), human immunodeficiency virus (HIV), intensive care unit (ICU), interferon stimulated response element (ISRE), interferon regulatory factor (IRF), main protease (Mpro), maximum serum concentration $\left(\mathrm{C}_{\max }\right)$, Medicines and Healthcare products Regulatory Agency (MHRA), Middle East respiratory syndrome coronavirus (MERS-CoV), monocyte chemoattractant protein 1 (MCP1), Multicentric Castleman's disease (MCD), multiple sclerosis (MS), non-steroidal anti-inflammatory drugs (NSAIDS), non-structural protein 14 (nsp14), P-glycoprotein (P-gp), pharmacokinetic (PK), phosphate (P), RNA-dependent RNA polymerase (RdRp), secondary haemophagocytic lymphohistiocytosis (sHLH), Severe acute respiratory syndrome coronavirus 2 (SARS-CoV-2), signal transducer and activator of transcription proteins (STAT), sulfobutylether $\beta$-cyclodextrin sodium (SBECD), thrombotic microangiopathy (TMA), tumour necrosis factor (TNF), upper limit of normal (ULN), World Health Organization (WHO).

\section{Introduction}

Severe acute respiratory syndrome coronavirus 2 (SARS-CoV-2) is a highly pathogenic beta-coronavirus that emerged in Wuhan, Hubei Province, in late December 2019 (X. Yang et al., 2020). SARS-CoV-2 is the seventh human coronavirus $(\mathrm{HCoV})$ to be identified and is the cause of the disease known as COVID-19 which was declared by the World Health Organization (WHO) as a "Public Health Emergency of International Concern" on 30 January 2020 (T. Liu et al., 2020). The symptoms of COVID-19 are non-specific and cover a broad clinical spectrum meaning that clinical diagnosis without a test is challenging. Patients commonly present with fever, cough and anosmia, although many patients are asymptomatic. The virus can be transmitted by asymptomatic patients alongside those in the symptomatic and pre-symptomatic phase of the disease (D. $\mathrm{Wu}, \mathrm{Wu}$, Liu, \& Yang, 2020; X. Yang et al., 2020). As of $6^{\text {th }}$ June 2020, COVID-19 is responsible for 395,459 deaths worldwide (John Hopkins University and Medicine, 2020). As the number of new cases continues to increase rapidly, many clinical and preclinical studies have been initiated to identify viable treatment options for COVID-19 patients. Many of these potential therapeutic strategies are based upon the re-purposing of approved drugs or the evaluation of those currently in the clinical stages of drug development (figure 1). For this reason, much information already exists on the pharmacology and toxicology of each prospective therapy. In order to examine their potential for efficacy and safety against COVID-19, it is essential to consider all of the available information in this extremely fast-moving and critical research field. Therefore, it is important to assess drug-specific safety parameters in the context of the pathogenesis of the virus and its clinical features in order to begin to evaluate the disease-specific harm-benefit ratio.

Therapeutic strategies for the treatment of COVID-19 span a range of phases including prophylactic administration, through to early infection, through to the more severe disease stage characterised by pulmonary involvement requiring mechanical ventilation and hyperinflammation in some instances (Siddiqi \& Mehra, 2020). At the time of writing, over 600 clinical trials have been initiated across the globe, with the majority of these investigating the use of a drug(s) already approved for treatment of another disease (Clinical Trials.gov, 2020b). In addition to their administration as a monotherapy, combination therapy has also been utilised. In addition to repurposed compounds, several candidates in preclinical or clinical development stages are also under-investigation, as well as widely available borderline substances such as ascorbic acid (Clinical Trials.gov, 2020d). However, it is important to note that the number of clinical trials initiated should not be taken as an indicator of the ultimate potential for success.

Our perspective will focus upon selected repurposed therapies which are used in different phases of the disease (figure 1), and can broadly be categorised by their mechanism of action as 1) viral entry inhibitors; 
2) disruption of cellular viral processing; 3) modulators of the inflammatory phase and 4) compounds that stimulate the host's anti-viral response. Selections were based upon agents undergoing the largest clinical trials at the time of writing, $6^{\text {th }}$ June 2020.

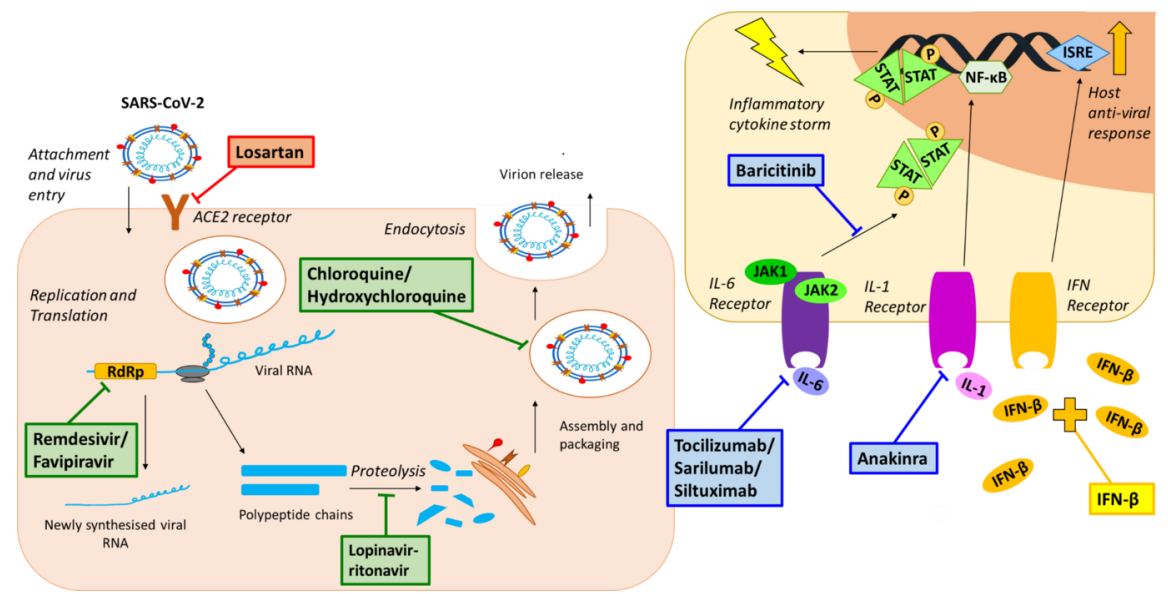

Figure 1: Overview of the mechanisms of action of the repurposed drugs undergoing clinical trials for the treatment of COVID-19 that will be reviewed in this perspective. Compounds in red represent those that are viral entry inhibitors, compounds in green represent disruptors of cellular viral processing, compounds in blue are modulators of the hyperinflammatory phase of infection and compounds in yellow stimulate host immunomodulatory and anti-viral activity. Abbreviations: ACE2, angiotensin converting enzyme 2; IL-6, interleukin-6; IL-1, interleukin- 1; JAK, janus kinase; RdRp, RNA-dependent RNA polymerases; STAT, signal transducer and activator of transcription proteins; $\mathrm{P}$, phosphate; $\mathrm{NF}-\varkappa \mathrm{B}$, nuclear factor kappa-lightchain-enhancer of activated B cells; IFN- $\beta$, interferon-beta; ISRE, interferon stimulated response element.

\section{Inhibitors of Epithelium Cell Entry}

It has been widely reported that angiotensin-converting enzyme 2 (ACE2) is likely to be the predominant cell surface receptor by which SARS-CoV-2 is able to enter host cells (Hoffmann et al., 2020). ACE2 is widely distributed in the body, but is particularly highly expressed on lung alveolar cells, which could explain the increased lung damage seen in some COVID-19 patients (Favalli et al., 2020; Zhao et al., 2020).

\subsection{Angiotensin receptor blockers (ARB)}

Losartan is an angiotensin receptor blocker (ARB) hypothesised to block the attachment of SARS-CoV-2 to cells expressing ACE2, thereby preventing viral entry into host cells (Gurwitz, 2020). Losartan is a welltolerated compound used in the treatment of hypertension, heart failure and diabetes (Goa \& Wagstaff, 1996; Ripley \& Hirsch, 2010). For these indications, losartan treatment is lifelong and is typically administered at a dose of $25-50 \mathrm{mg}$ once a day, which can be increased to $100 \mathrm{mg}$ if tolerated and deemed necessary (Dohme, 2003). Clinical trials for losartan use in COVID-19 are currently recruiting patients. Whilst exact dosing regimens vary between the trials, they are based upon the standard dose and will see patients given $25-50 \mathrm{mg}$ daily losartan treatment for 7 - 14 days (clinical trials identifiers: NCT04335123, NCT04312009 and NCT04311177).

When used for its intended therapeutic conditions, losartan is considered to be a relatively safe compound. The most common adverse events (AEs) reported during clinical trials were headache, dizziness, fatigue and hypotension (Goa \& Wagstaff, 1996; Usai et al.; Weber, 1997). Laboratory findings during clinical trials reported mild elevations in alanine aminotransferase (ALT) but these were self-limiting and did not result in acute liver failure (Goa \& Wagstaff, 1996). More recently, cases of losartan-induced hepatotoxicity have been reported, albeit rarely (LiverTox, 2017a). Losartan is associated with serious cases of foetal toxicity 
and so cannot be administered to women in the second and third trimesters of pregnancies (Nayar, Singhal, Aggarwal, \& Malhotra, 2003).

There is controversy regarding the use of losartan in COVID-19 trials as the expression of ACE2 can be significantly increased following ARB treatment. However, contradictory results for the potential of ARBinduced ACE2 upregulation have also been reported (Ferrario et al., 2005; Klimas et al., 2015; Tignanelli et al., 2020). Given that ACE2 is already highly expressed within the lungs, a further increase in ACE2 expression may have the potential to increase viral entry into the lungs, thus exacerbating the potential for pulmonary involvement (Fang, Karakiulakis, \& Roth, 2020). Evidence of increased myocardial injury and chronic damage to the cardiovascular system have been reported in patients infected with SARS-CoV2 (Zheng, Ma, Zhang, \& Xie, 2020). ACE2 is also expressed within the cardiovascular system and it has been suggested that this may underlie cardiac effects via enhanced viral entry into the myocardium (Zheng et al., 2020). It is important to note that human data thus far does not support the hypothesis that ARBs (and ACE-inhibitors) increase the risk of severe COVID-19 disease since epidemiological studies have largely shown either a protective effect or no adverse effects on mortality in COVID-19 (Tignanelli et al., 2020). Importantly, the latest advice from the Medicines and Healthcare products Regulatory Agency (MHRA) recommends those taking ARBs and ACE inhibitors for high blood pressure should continue doing so (Medicines and healthcare products Regulatory Agency, 2020a). Data from clinical trials for losartan in COVID-19 will provide additional safety data and much needed clarification on the role of ARBs and ACE2 in COVID-19.

Losartan has an overall favourable drug-drug interaction (DDI) profile, however concerns over the use of losartan and non-steroidal anti-inflammatory drugs (NSAIDs) during COVID-19 treatment have been raised (Sica, Gehr, \& Ghosh, 2005). Evidence initially suggested that there was a theoretical potential for NSAIDs to worsen COVID-19 symptoms. However, the Commission on Human Medicines deemed that there was insufficient evidence to confirm this association and that NSAIDs were safe to use in individuals with symptoms of COVID-19 (Commission on Human Medicines, 2020; Torjesen, 2020). However, NSAIDs have the potential to attenuate the effects of losartan to reduce hypertension thereby leading to an increase in blood pressure, which would be an undesirable side-effect in COVID-19 patients with hypertension, lung inflammation and cardiac damage (Pavlicević, Kuzmanić, Rumboldt, \& Rumboldt, 2008). In such patients, BP should be closely monitored.

\section{Disruptors of Cellular Viral Processing}

\subsection{Lopinavir-ritonavir}

Lopinavir-ritonavir is a fixed dose combination of drugs branded as Kaletraß. It was developed for the treatment of human immunodeficiency virus (HIV) disease. Lopinavir is a protease inhibitor that is coadministered with ritonavir to improve the pharmacokinetic (PK) properties of the drug (Chu et al., 2004). Lopinavir-ritonavir is a potential treatment for COVID-19 as it targets and deactivates the main protease (Mpro), which is involved in polyprotein processing and virus maturation (Dayer, Taleb-Gassabi, \& Dayer, 2017). A standard dose of lopinavir-ritonavir is $400 \mathrm{mg} / 100 \mathrm{mg}$ twice a day for HIV-1 treatment, and this has also been used for SARS-CoV-2 treatment (Cao et al., 2020).

The most frequent reported AEs for lopinavir-ritonavir treatment are gastrointestinal disturbances including diarrhoea, nausea and vomiting (Chandwani \& Shuter, 2008). Dose-related diarrhoea have been reported in up to $25 \%$ of patients and are thought to occur through a number of mechanisms including decreased proliferation of intestinal epithelial cells, disruption of intestinal barrier function, inducing endoplasmic reticulum stress and activating the unfolded protein response (X. Wu, Li, Peng, \& Zhou, 2014). Diarrhoea is also a symptom in some COVID-19 patients and so lopinavir-ritonavir has the potential to exacerbate this. Pancreatitis has been reported in a small number of patients following lopinavir-ritonavir treatment although this was more frequent in those with a pre-existing history of pancreatitis (Chandwani \& Shuter, 2008; Oldfield \& Plosker, 2006). Additionally, patients with underlying liver diseases should have regular monitoring of hepatic function (Palacios et al., 2006). Caution should be exerted for those patients taking 
concomitant medication as lopinavir-ritonavir inhibits P-glycoprotein (P-gp) and cytochrome P450 (CYP) -3A4, which therefore may alter the PK of other compounds (L. Zhang, Zhang, \& Huang, 2009). A COVID-19 drug interaction website has been developed by The Liverpool Drug Interaction Group which details DDIs with lopinavir-ritonavir and a number of drugs, which in some cases can lead to potentially serious and/or life-threatening reactions (Group, 2020; AbbVie Inc., 2016).

Since the SARS-CoV-2 outbreak, 73 clinical trials have been registered (up to $6^{\text {th }}$ June 2020) to test lopinavirritonavir as a potential treatment for SARS-CoV-2 with variable outcomes in terms of efficacy. In one trial of 199 patients with confirmed SARS-CoV-2, 13 patients on the lopinavir-ritonavir arm were withdrawn due to AEs (Cao et al., 2020). In a different trial, patients who were administered lopinavir-ritonavir (200 mg/ $50 \mathrm{mg}$ ) also experienced gastrointestinal AEs (Li et al., 2020).

\subsection{Chloroquine and hydroxychloroquine}

Chloroquine and its derivative, hydroxychloroquine, are widely used as inexpensive and safe anti-malarial drugs. In particular, the established good tolerability of chloroquine/hydroxychloroquine has made them safe to use even in pregnancy (Villegas et al., 2007). In addition to anti-malarial activity, both drugs have immunomodulating effects and are used for the treatment of autoimmune diseases including systemic and discoid lupus erythematosus, psoriatic arthritis, and rheumatoid arthritis. Chloroquine/hydroxychloroquine concentrate extensively in acidic vesicles including the endosomes, Golgi vesicles, and the lysosomes (Ohkuma \& Poole, 1981). This leads to lysosomal membrane permeabilisation or dysfunction of several enzymes including acid hydrolases and palmitoyl-protein thioesterase 1 (Rebecca et al., 2019; Savarino, Boelaert, Cassone, Majori, \& Cauda, 2003; Schrezenmeier \& Dorner, 2020). Although the precise mechanisms of the anti-viral effects are not fully understood, it has been proposed that chloroquine/hydroxychloroquine can prevent virus infection (pre-infection) by interfering with the glycosylation of cellular receptors and impair viral replication by increasing endosomal pH (post-infection) (Savarino et al., 2003; Savarino et al., 2004; Vincent et al., 2005).

Owing to their efficacy against viruses (mostly demonstrated in vitro ) including influenza, HIV, coronavirus OC43, and SARS-CoV, a large number of clinical trials (>160) have been registered worldwide using chloroquine/hydroxychloroquine alone, or in combination with other drugs (e.g. azithromycin) for the treatment of COVID-19. Despite promising in vitro antiviral results for hydroxychloroquine/chloroquine, there is no convincing evidence of efficacy at present (Gao, Tian, \& Yang, 2020; Gautret, Lagier, Parola, Hoang, Meddeb, Mailhe, et al., 2020; Gautret, Lagier, Parola, Hoang, Meddeb, Sevestre, et al., 2020; J. Liu et al., 2020; Magagnoli, 2020; Mathian et al., 2020; Million et al., 2020; Tang, 2020; Yao et al., 2020). A post-exposure prophylaxis randomised controlled trial of 821 participants failed to show any benefit of hydroxychloroquine $(\mathrm{n}=414)$ compared with placebo $(\mathrm{n}=407)$ (Boulware et al., 2020). At the time of writing, the RECOVERY trial (clinical trial identifier NCT04381936) which is the largest randomised control trial so far conducted for the treatment of COVID, has stopped recruiting to the hydroxychloroquine arm (1542 patients compared with 3132 on standard care) because of no beneficial effect either in terms of mortality or hospital stay (Horby \& Landray, 2020). There are still many other trials on-going testing the efficacy of hydroxychloroquine for either prophylaxis or treatment.

Both chloroquine and hydroxychloroquine have been in clinical use for many years for rheumatoid diseases, and thus their safety profile is well established. Dose-dependent retinal toxicity has long been recognized as the major AE with long-term use of chloroquine/hydroxychloroquine (Marmor et al., 2011). Besides retinal toxicity, gastrointestinal, liver and renal toxicity have also been reported (Giner Galvan, Oltra, Rueda, Esteban, \& Redon, 2007; Michaelides, Stover, Francis, \& Weleber, 2011; Mittal, Zhang, Feng, \& Werth, 2018). As both drugs are mainly metabolised in the liver and excreted by renal clearance, their use in patients with liver or renal impairment may worsen the function of these organs. For chloroquine treatment, prescribing information recommends the full dose at all degrees of renal impairment but suggests that monitoring of renal function may be useful (Sanofi-Aventis, 2017 ). For hydroxychloroquine, reductions in dosage are advised for patients with impaired renal function, as well as those taking concomitant medications with known risks of kidney damage (Concordia Pharmaceuticals Inc, 2017). 
A serious $\mathrm{AE}$ associated with chloroquine/hydroxychloroquine is cardiotoxicity, which can take many forms including cardiomyopathy in rare instances. Prolonged treatment or high dosage of chloroquine/hydroxychloroquine has been shown to increase of the risk of QT interval prolongation, polymorphic ventricular tachycardia, and sudden cardiac death (Chatre, Roubille, Vernhet, Jorgensen, \& Pers, 2018). A large epidemiological analysis in patients with rheumatoid arthritis has recently shown that 30-day cardiovascular mortality was increased by more than 2 -fold when hydroxychloroquine was combined with azithromycin. The lethal ventricular arrhythmias are primarily due to inhibition of a potassium channel (the inward rectifier Kir2.1 channel) and may occur at low $\mu \mathrm{M}$ concentrations $\left(\mathrm{IC}_{50}=8.7 \mu \mathrm{M}\right)$ (Rodriguez-Menchaca et al., 2008). While therapeutic doses of chloroquine typically result in plasma concentrations of 2-5 $\mu \mathrm{M}$, much higher concentrations in the heart are expected based on a 400-fold increase observed in rat PK studies (McChesney, Banks, \& Fabian, 1967; Walker, Dawodu, Adeyokunnu, Salako, \& Alvan, 1983). The binding of chloroquine to the inward rectifier Kir2.1 channel can be stabilized by negatively charged and aromatic amino acids (Rodriguez-Menchaca et al., 2008). The binding of chloroquine/hydroxychloroquine to proteins is also stereoselective, but whether one of the chloroquine/hydroxychloroquine enantiomers has a stronger interaction with the Kir2.1 channel is not known. Caution is needed when hydroxychloroquine is used in combination with other drugs (including azithromycin), which increase the QT interval because of a pharmacodynamic synergistic interaction.

Given the comorbidities in many patients with COVID-19, especially those with underlying cardiovascular disease, and the fact that COVID-19 itself is associated with cardiac manifestations, this may increase the risk of cardiotoxicity associated with the use of chloroquine/hydroxychloroquine. Indeed, excessive QTc prolongation was observed in $36 \%$ of patients as reported by Bessiere at al. and greater QTc prolongation was also seen in patients taking the combination of hydroxychloroquine and azithromycin than those taking hydroxychloroquine alone, highlighting the importance of pharmacodynamic interactions (Bessiere et al., 2020; Mercuro et al., 2020). Furthermore, a phase IIb trial in Brazil showed that a higher dose of chloroquine (600 mg twice daily) in patients hospitalised with COVID-19 had a higher fatality rate (30\%) compared with $15 \%$ in the lower dose (450 mg twice daily) group (Borba et al., 2020). QTc interval prolongation $>500 \mathrm{msec}$ was observed in $19 \%$ of the high dose group compared with $11 \%$ of the low dose group. The US prophylaxis randomised control trial however did not show any increase in cardiovascular AEs (Boulware et al., 2020). We await the publication of the RECOVERY trial to determine whether there was an excess of cardiovascular events. However, it is important to note that despite the size of the RECOVERY trial (n $=1542$ patients), it may still be under-powered to identify an excess number of cardiovascular events when compared with standard of care.

\subsection{Remdesivir}

Remdesivir is an investigational compound that was developed for the treatment of Ebola (Mullard, 2018; Tchesnokov, Feng, Porter, \& Gotte, 2019). Remdesivir is a monophosphoramidate prodrug and acts as a broad-spectrum antiviral that can be incorporated into viral RNA (Agostini et al., 2018; Sheahan, Sims, Leist, Schafer, et al., 2020; T. K. Warren et al., 2016). Many anti-virals are proving to be ineffective against COVID-19 due to the presence of a proofreading exoribonuclease (ExoN) specific to coronaviruses, encoded in non-structural protein 14 (nsp14) (Agostini et al., 2018). Remdesivir is able to evade this viral proofreading, meaning its incorporation into viral RNA results in the inhibition of RNA-dependent RNA polymerases (RdRps), thereby preventing subsequent viral replication (Travis K. Warren et al., 2016). Furthermore, Arshad et al. suggest that the maximum serum concentration $\left(\mathrm{C}_{\max }\right)$ of remdesivir is sufficient to inhibit 90 $\%$ of SARS-CoV-2 replication, a parameter which is suspected to be of vital importance in the treatment of COVID-19 (Arshad et al., 2020).

Remdesivir is administered intravenously, with single doses ranging between 3 to $225 \mathrm{mg}$ being well tolerated in Ebola patients $(\mathrm{n}=8)$ (Clinical Trials.gov, 2019). Similar observations were made in the blinded, placebocontrolled multiple-dose studies, during which Ebola patients $(n=8)$ received an intravenous infusion of $150 \mathrm{mg}$ remdesivir daily for either 7 or 14 days; only grade 1 and 2 adverse reactions were reported (Clinical Trials.gov, 2019). The proposed dosing regimen for COVID-19 patients receiving remdesivir via the UK 
Early Access to Medicines Scheme (EAMS) is similar to that which was evaluated for Ebola treatment: a loading dose of $200 \mathrm{mg}$ on day 1, followed by $100 \mathrm{mg}$ daily for 5 - 10 days depending on symptom severity (Medicines and Healthcare products Regulatory Agency, 2020b). As such, it is likely that many of the AEs observed in the Ebola study will translate to COVID-19 patients treated with remdesivir.

Mild to moderate ALT and aspartate transaminase (AST) elevations were observed in several Ebola patients during the multiple-dose study, thus reflecting observations made in human hepatocytes in vitro(Clinical Trials.gov, 2019; World Health Organisation, 2018). This is likely to be due to the high cell permeability of hepatocytes, in combination with the effective intracellular metabolism of remdesivir to its active form within the liver (World Health Organisation, 2018). Emerging data has suggested that SARS-CoV-2 may target ACE2 on hepatocytes leading to liver injury as evidenced by a significant increase in ALT and bilirubin in severe cases of COVID-19 (Guan et al., 2020). Therefore, it is likely that differentiating between COVID19-induced transaminase elevations and those induced by remdesivir presents challenges (Bangash, Patel, \& Parekh, 2020; C. Zhang, Shi, \& Wang, 2020). However, a recent study found that only $4.1 \%$ of COVID-19 patients receiving remdesivir treatment suffered serious (grade 3 or 4) transaminase elevations, with there being no significant difference between the remdesivir- and placebo-treated groups (Beigel et al., 2020). This data implies that remdesivir is relatively well-tolerated in SARS-CoV-2-positive patients. Regardless, as advised by the drug manufacturer, daily liver function tests are essential in any patients receiving remdesivir, with suggested discontinuation of the drug in patients whose ALT levels reach [?] 5 times the upper limit of normal (ULN) (Gilead, 2020). Adhering to these guidelines is of particular importance in patients with pre-existing liver disease, or in those taking other medications which can also induce transient ALT and AST elevation (World Health Organisation, 2018).

The reported differences between preclinical and clinical data regarding the safety of remdesivir highlight the inadequacies of preclinical models in some contexts. For example, with regards to COVID-19, a concerning element of theoretical toxicity is that which affects the respiratory system. A study using mice models of Middle East respiratory syndrome coronavirus (MERS-CoV) found remdesivir improved pulmonary pathology in infected mice and rhesus monkeys, and no respiratory toxicity was observed (Gilead, 2020; Sheahan, Sims, Leist, Schafer, et al., 2020). In contrast, a respiratory safety study in rats showed that remdesivir had no impact on tidal volume or minute volume, but did increase respiratory rate, which returned to baseline by 24 hours post-dose (World Health Organisation, 2018). Clearly, increased respiratory rate is a manifestation of COVID-19, and there would be problems in assessing causality if remdesivir was also likely to cause of respiratory problems in a clinical setting. Fortunately, a recent double-blind, randomized, placebo-controlled trial showed there to be no significant differences in adverse respiratory events between the remdesivir-treated and control arms (Beigel et al., 2020). In addition to this, preclinical safety studies performed in rats and cynomolgus monkeys suggested that the kidney was the target organ for remdesivirinduced toxicity (Gilead, 2020). This was a significant concern before the initial COVID-19 clinical trials, as it is known that SARS-CoV-2 can cause acute kidney failure in severe cases (Ronco, Reis, \& Husain-Syed, 2020). However, this has not been reflected in COVID-19 clinical trials, where the presence of biomarkers indicative of renal injury have not differed in patients treated with remdesivir compared to those on placebo (Beigel et al., 2020; Gilead, 2020). However, due to the inclusion of the solubility enhancer sulfobutylether $\beta$-cyclodextrin sodium (SBECD) within remdesivir formulations, remdesivir is contraindicated in patients with severe renal impairment (eGFR $<30 \mathrm{ml} / \mathrm{min}$ ) (European Medicines Agency, 2020).

Finally, remdesivir is not exempt from DDIs. Co-administration of remdesivir with several antibiotics including rifampicin is contraindicated, which could cause problems for any patients being treated concomitantly for tuberculosis (Group, 2020). This occurs because of enzyme induction which reduces systemic exposure to remdesivir. A similar interaction has also been seen with enzyme-inducing anticonvulsants, including carbamazepine, phenytoin, and phenobarbital (Group, 2020), where reduction in remdesivir exposure may lead to inadequate treatment of COVID-19.

\subsection{Favipiravir}

Favipiravir is another broad-spectrum anti-viral prodrug which undergoes intracellular phosphoribosyla- 
tion to produce its active form, favipiravir-ribofuranosyl-5'-triphosphate (favipiravir-RTP) (Yousuke Furuta, Komeno, \& Nakamura, 2017). It is thought that this anti-viral primarily acts by inducing lethal mutagenesis of RNA viruses, although it also selectively and potently inhibits viral RdRp by acting as a pseudo purine nucleotide (Dawes et al., 2018; Sangawa et al., 2013). Favipiravir is currently licensed in Japan for the treatment of novel and re-emerging influenza (Yousuke Furuta et al., 2013; Y. Furuta et al., 2002). Its extensive spectrum of activity against various RNA virus polymerases led to favipiravir being cited as a potentially 'crucial pandemic tool', even before the outbreak of the novel coronavirus, COVID-19 (Adalja \& Inglesby, 2019).

The PK of favipiravir was initially characterised in healthy Japanese volunteers (Madelain et al., 2016). A $\mathrm{C}_{\max }$ of $51.5 \mu \mathrm{g} / \mathrm{mL}$ was found to occur 2 hours post-administration, but plasma concentrations decreased rapidly due to the relatively short half-life of favipiravir (between 2 and 5.5 hours) (Madelain et al., 2016). However, both $\mathrm{C}_{\max }$ and half-life increase slightly after multiple doses and it has been suggested that favipiravir is capable of reaching a $\mathrm{C}_{\max }$ in humans sufficient to inhibit $90 \%$ of SARS-CoV-2 replication, thus establishing it as an important compound in the ongoing search for COVID-19 therapies (Arshad et al., 2020).

Marked differences in $\mathrm{C}_{\max }$ have been observed between Japanese and American patients with $\mathrm{C}_{\max }$ values in Japanese subjects being on average $13.26 \mu \mathrm{g} / \mathrm{mL}$ greater than those in American subjects (PMDA, 2014). This highlights the need for relevant COVID-19 clinical trials to include a diverse range of subjects so that factors such as weight and ethnicity can be considered to optimise dose. The bioavailability of favipiravir is high at $97.6 \%$ and only $54 \%$ of the drug is plasma protein-bound, suggesting high tissue penetration would be likely (Madelain et al., 2016; PMDA, 2014). In vivo work in mice showed that the half-life of favipiravir in the lungs is double that of favipiravir in plasma, indicating slower elimination from the lungs (PMDA, 2014). This is thought to be of high importance in COVID-19, where viral load is particularly high in the lungs. For influenza treatment in adults, $1600 \mathrm{mg}$ favipiravir is given twice on day 1 of treatment, followed by $600 \mathrm{mg}$ twice daily from days 2 to 5 (PMDA, 2014). However, the dosing period has been extended in ongoing COVID-19 clinical trials: up to 10 days in ChiCTR2000029996 and 14 days in ChiCTR2000029548 (Guan et al., 2020; "Identifier ChiCTR2000029996, A randomized, open-label, controlled trial for the efficacy and safety of Farpiravir Tablets in the treatment of patients with novel coronavirus pneumonia (COVID19)," 2020). It is therefore essential that all PK parameters are monitored in these trials as differences, including increased $\mathrm{C}_{\max }$ and decreased clearance, are expected during this prolonged dosing regimen which may impact upon safety.

Favipiravir has been linked to teratogenicity and embryotoxicity, and is therefore contraindicated in pregnancy (Yousuke Furuta et al., 2013). Overall, favipiravir is generally thought to have a good safety profile (Asrani, Devarbhavi, Eaton, \& Kamath, 2019; Group, 2020; NHS, 2019). This is likely to be due to the fact that unlike other antiviral drugs such as ribavirin, favipiravir does not appear to disrupt non-viral RNA or DNA synthesis. However, very little is known about the long-term safety of favipiravir, as in previous clinical trials patient follow-up has been as little as 5 days (Pilkington, Pepperrell, \& Hill, 2020). This is perhaps less of a concern in COVID-19 as treatment is time-limited.

Drug-drug interactions have been reported with favipiravir. For example, coadministration with favipiravir can increase exposure to paracetamol by around $15 \%$, which may be a concern for patients with preexisting liver disease as paracetamol is the leading cause of acute drug-induced liver injury (DILI) in the UK and USA (Asrani et al., 2019; Group, 2020). Favipiravir can also increase patient exposure to many contraceptives, including progesterone-only pills, combined pills, and several contraceptive implants, which may cause discomfort, prolonged vaginal bleeding, and nausea (Group, 2020; NHS, 2019). Whether the increased exposure to oestrogens caused by concomitant treatment with favipiravir can enhance the risk of thrombosis is not known but should be monitored, given the overwhelming evidence that COVID-19 increases the risk of blood clots (Atallah, Mallah, \& AlMahmeed, 2020; Di Micco et al., 2020; Spiezia et al.). Interestingly, large clots are most common in patients under the age of 50 ; almost $25 \%$ of women aged between 15 - 49 in the USA currently use either oral or long-acting contraceptives, and thus represent 
a particular risk group (Hurley, 2020; Prevention, 2019).

\section{Modulation of the Inflammatory Phase}

SARS-CoV-2 virus is capable of eliciting an immune reaction in the infected individual. Laboratory examinations have revealed that inflammatory factors such as interleukin (IL)-6, IL-1, IL-10 and tumour necrosis factor- $\alpha(\mathrm{TNF} \alpha)$ are upregulated during infection and can instigate an inflammatory response in the lower airways leading to lung injury in some instances (Conti et al., 2020; Guo et al., 2020). Additionally, in patients with severe symptoms of COVID-19, there may be activation of a cytokine storm, which can cause significant tissue damage (Mehta, McAuley, et al., 2020; Shi et al., 2020). A smaller proportion of patients can progress to a hyper-inflammatory state which in COVID-19 has been suggested to resemble secondary haemophagocytic lymphohistiocytosis (sHLH), a rare syndrome characterised by uncontrollable fever, cytopenia, raised ferritin levels and acute respiratory distress (Seguin, Galicier, Boutboul, Lemiale, \& Azoulay, 2016). Interleukin and TNF- $\alpha$ levels show the greatest increase in those who require admission to the intensive care unit (ICU), suggesting that the cytokine storm is instrumental in severe COVID-19 cases (Huang et al., 2020). Therefore, there has been a logical progression towards the use of immunosuppressive agents as potential therapies to alleviate inflammation and hyperinflammation associated with COVID-19 (Mehta, McAuley, et al., 2020).

\subsection{IL-6 Receptor Inhibitors}

Both tocilizumab and sarilumab are humanised anti-IL-6 receptor monoclonal antibodies used for the treatment of moderate - severe rheumatoid arthritis, whereas siltuximab is a chimeric, human-mouse anti-IL-6 receptor monoclonal antibody used for treatment of Multicentric Castleman's disease (MCD) (Deisseroth et al., 2015; National Institute for Health and Care Excellence, 2020c). Due to their long half-life, IL-6 inhibitors do not need to be taken daily; however, given that they are currently indicated for chronic diseases, patients receive IL-6 inhibitor treatments for life or until treatment failure (Janssen Biotech Inc; Roche Pharma; Sanofi-Aventis).

Clinical trials to assess the efficacy and safety of tocilizumab, sarilumab and siltuximab for the treatment of the inflammatory phase of COVID-19 are ongoing. Whilst the exact dosing regimens vary between trials, COVID-19 patients will be receiving a single or short course intravenous infusion or subcutaneous injection of the IL-6 inhibitor (clinical trial identifiers NCT04317092, NCT04315298, NCT04327388, NCT04330638, NCT04322188).

Due to their similarity, it is not surprising that tocilizumab, sarilumab and siltuximab have comparable safety profiles. Thus far, evidence from clinical trials in patients with rheumatoid arthritis and MCD or post-marketing have revealed that IL-6 inhibitors are generally well-tolerated. Participants were enrolled on these trials for a minimum of 6 months and in some cases up to 24 months. Individuals with diabetes, a history of recurrent infection, age [?] 65 and corticosteroid use have been shown to be at an increased risk of developing a more serious infection following IL-6 inhibitor use (Jones et al., 2010). Whilst adverse reactions were typically seen following chronic IL-6 inhibitor treatment, the potential for COVID-19 patients to develop an adverse drug reaction (ADR) following a single or small number of doses should not be ignored.

The most common infections reported in patients receiving anti-IL6 therapy include skin infections, respiratory infections, urinary tract infections and in some cases, opportunistic infections ranging from tuberculosis to herpes (Emery et al., 2008; Emery et al., 2019; R. Fleischmann et al., 2017; R. M. Fleischmann et al., 2013; M. C. Genovese et al., 2015; Mark C Genovese et al., 2008; M. C. Genovese et al., 2019; Hoshi et al., 2012; Huizinga et al., 2014; Janssen Biotech Inc, 2019; Jones et al., 2010; Kameda et al., 2020; McCarty \& Robinson, 2018; Pawar et al., 2019; J. S. Smolen et al., 2008; Tanaka et al., 2019; Weinblatt et al., 2013). Neutropenia has also been reported with all 3 drugs when tested for their intended therapeutic use, and in some trials, this led to patient discontinuation (Emery et al., 2008; R. Fleischmann et al., 2017; R. M. Fleischmann et al., 2013; M. C. Genovese et al., 2015; Mark C Genovese et al., 2008; Huizinga et al., 2014; Janssen Biotech Inc, 2019; Jones et al., 2010; J. S. Smolen et al., 2008). Absolute neutrophil count (ANC) must be monitored every $4-8$ weeks and in those who develop an ANC $<0.5 \times 10^{9} / \mathrm{L}$, treatment must be 
discontinued (National Institute for Health and Care Excellence; Roche Pharma; Sanofi-Aventis). Gastrointestinal manifestations (upper abdominal pain, mouth ulceration and nausea) have also been reported with IL-6 inhibitors. A systematic review and meta-analysis of 35 COVID-19 studies found that $15 \%$ of patients experienced gastrointestinal disturbance manifested as vomiting, diarrhoea and loss of appetite. This has been postulated to be due to the expression of ACE2 on gastrointestinal epithelial cells (Mao et al., 2020; Qi, Qian, Zhang, \& Zhang, 2020). Therefore, differentiating between COVID-19-induced gastrointestinal disorders and those evoked by IL- 6 therapy may present a challenge in terms of causality and the need to modify or stop therapy. Increases in lipid profiles (total cholesterol, low-density lipoprotein, high-density lipoprotein and triglycerides) have also been reported in patients receiving IL-6 inhibitors as either monotherapy or combination therapy (Emery et al., 2008; R. M. Fleischmann et al., 2013; M. C. Genovese et al., 2015; Mark C Genovese et al., 2008; M. C. Genovese et al., 2019; Huizinga et al., 2014; Janssen Biotech Inc, 2019; Jones et al., 2010; Kameda et al., 2020; J. S. Smolen et al., 2008; Tanaka et al., 2019). However, the incidence of major cardiovascular events was infrequent, and lipid elevation resolved with statin therapy (M. C. Genovese et al., 2015; M. C. Genovese et al., 2019).

Tocilizumab is associated with an increased risk of hepatotoxicity, usually manifested as an asymptomatic rise in ALT (Anger et al., 2017; Drepper, Rubbia-Brandt, \& Spahr, 2013; R. M. Fleischmann et al., 2013; Jones et al., 2010; Mahamid, Mader, \& Safadi, 2011; Maini et al., 2006; Nishimoto et al., 2009; Pawar et al., 2019; J. S. Smolen et al., 2008). Liver injury has also been reported with a liver biopsy from a female patient who had taken tocilizumab for a month revealing focal necrosis of hepatocytes with steatosis and early fibrosis (Mahamid et al., 2011). COVID-19 also has effects on the liver, and again causality assessment may be difficult (Guan et al., 2020). The prescribing instructions for tocilizumab and sarilumab indicate that liver function tests are required every $4-8$ weeks following treatment commencement and then every 3 months thereafter (Roche Pharma; Sanofi-Aventis). If liver enzymes are $1-3 \times$ ULN, the dose of tocilizumab and sarilumab can be reduced until ALT or AST have normalised and then treatment resumed at the therapeutic dose. Where laboratory findings are $>3-5 \times$ ULN, treatment with IL-6 inhibitors must be paused and then recommendations for $1-3 \mathrm{x}$ ULN followed. If elevations persist or are $>5 \mathrm{x}$ ULN, tocilizumab and sarilumab treatment must be discontinued immediately (Roche Pharma; Sanofi-Aventis). Whilst sarilumab and siltuximab are associated with abnormalities in liver function tests, they are typically short-lived and asymptomatic (LiverTox, 2016, 2017b). Pre-existing liver disease can worsen symptoms of DILI, and in some cases increase susceptibility (David \& Hamilton, 2010).

Tocilizumab, sarilumab and siltuximab are expected to undergo metabolism via catabolic pathways and not CYP450 processes (McCarty \& Robinson, 2018). Therefore, due to the lack of hepatic metabolism, it is assumed that the PK of the IL-6 inhibitors will not be altered in patients with pre-existing liver disease (Abou-Auda \& Sakr, 2010). However, tocilizumab, sarilumab and siltuximab have been shown to restore and improve CYP levels (Janssen Biotech Inc, 2019; Roche Pharma, 2013; Sanofi-Aventis, 2017). This is of particular importance as CYP levels may remain elevated following treatment discontinuation due to the long half-life of the compounds. Therefore, this may be a consideration for further evaluation for any dosing adjustment requirements if patients are taking medication that are metabolised by CYP enzymes.

\subsection{IL-1 Receptor Inhibitors}

Anakinra is a $17 \mathrm{kD}$, recombinant human IL-1 receptor antagonist that blocks the activity of proinflammatory cytokines IL- $1 \alpha$ and IL-1 $\beta$ (Cawthorne et al., 2011; Dinarello, Simon, \& van der Meer, 2012). Anakinra is primarily used in combination with methotrexate for reducing the symptoms and slowing the progression of joint damage in rheumatoid arthritis (National Institute for Health and Care Excellence, 2020a). It is also used for rare inflammatory conditions such as Cryopyrin-associated periodic syndromes and Still's disease (National Institute for Health and Care Excellence, 2020a). It is administered via subcutaneous injection and is supplied as a single-use, pre-filled syringe containing $100 \mathrm{mg} / 0.67 \mathrm{~mL}$ (Swedish Orphan Biovitrum Ltd, 2007). Rheumatoid arthritis patients and those with Still's disease and a body weight $>50 \mathrm{~kg}$ must be administered $100 \mathrm{mg}$ anakinra, while patients with Still's disease with a body weight $<50 \mathrm{~kg}$ should have weight-based dosing starting at $1-2 \mathrm{mg} / \mathrm{kg}$ (Swedish Orphan Biovitrum Ltd, 
2007). The recommended starting dose for patients with Cryopyrin-associated periodic syndromes is 1-2 $\mathrm{mg} / \mathrm{kg}$. If tolerated, the dose can be increased to $3-4 \mathrm{mg} / \mathrm{kg}$ to a maximum of $8 \mathrm{mg} / \mathrm{kg}$ (Swedish Orphan Biovitrum Ltd, 2007). Anakinra has a short terminal half-life of approximately $4-6$ hours and so must be administered daily, preferably at the same time each day (Amgen Inc., 2001). Anakinra is currently not licensed for intravenous administration or treatment of sHLH but its use is endorsed by clinicians, where intravenous infusion, as opposed to subcutaneous injection, can achieve quicker and greater maximal plasma concentrations (Carter, Tattersall, \& Ramanan, 2018; La Rosée et al., 2019; Mehta, Cron, Hartwell, Manson, \& Tattersall, 2020).

Thus far, 16 clinical trials have been registered to assess the use of anakinra in patients with severe COVID19. Additionally, 2 recent studies have reported positive outcomes with anakinra in COVID-19 induced acute respiratory distress syndrome (Cavalli et al., 2020; Clinical Trials.gov, 2020c; Huet et al., 2020). Participants were dosed $100 \mathrm{mg}$ twice daily subcutaneously for 72 hours followed by $100 \mathrm{mg}$ daily for 7 days in addition to standard of care (Huet et al., 2020). This retrospective study found that anakinra reduced rates of mortality and the need for mechanical ventilation in ICU patients (Huet et al., 2020). Anakinra was administered either subcutaneously or intravenously in the COVID-19 Biobank Study (Huet et al., 2020). Participants received subcutaneous injections at a dose of $100 \mathrm{mg}$ twice daily or via slow intravenous infusion at $10 \mathrm{mg} / \mathrm{kg}$ per day until there was a $75 \%$ reduction in serum C-reactive protein levels and sustained respiratory improvements (Cavalli et al., 2020). Whilst no safety concerns emerged with anakinra administered subcutaneously, it was discontinued due to a lack of clinical improvement and limited reduction in C-reactive protein (Cavalli et al., 2020). By contrast, intravenous anakinra was well-tolerated and improved clinical outcomes. Notably, $72 \%$ of patients had improved respiratory function in comparison to $50 \%$ within the standard treatment group (Cavalli et al., 2020). In both studies, cases of ALT [?]3 x ULN were observed in both the anakinra and the standard treatment arms. Four cases of bacteraemia following intravenous anakinra were reported in the COVID-19 Biobank Study, but there were no cases of bacterial infection in the Ana-COVID Study (Cavalli et al., 2020; Huet et al., 2020). Whilst both studies are encouraging, they should be considered proof-of-concept trials and larger randomised trials are still needed (Cavalli et al., 2020; Huet et al., 2020).

Subcutaneous administration of anakinra is associated with injection site reactions (Kaiser et al., 2012). In a review of 5 rheumatoid arthritis clinical trials, $71 \%$ of participants receiving anakinra therapy reported injection site reactions in comparison to $28 \%$ of participants on placebo (Mertens \& Singh, 2009). Injection site reactions can range from immediate to delayed. In immediate cases, the reaction manifests as a burning sensation whereas delayed reactions present as a rash, pruritus or swelling (Kaiser et al., 2012). Anakinra has also been reported to lead to infection, neutropenia, thrombocytopenia, headache, and blood cholesterol increase when administered subcutaneously (Swedish Orphan Biovitrum Ltd, 2007).

Injection site reactions that arise immediately can be eased by placing an ice pack on the injection site before and after anakinra administration and delayed reactions can be treated with topical corticosteroids or antihistamines (Kaiser et al., 2012). Increases in serious infection rate are common following anakinra use and frequently include upper respiratory infections, sinusitis, urinary tract infection and bronchitis (Bresnihan et al., 1998; Cohen et al., 2002; R. M. Fleischmann et al., 2003). Whilst rare, cases of opportunistic infection have been reported in anakinra monotherapy or in those receiving anakinra in combination with immunosuppressive agents (Salvana \& Salata, 2009; Swedish Orphan Biovitrum Ltd, 2007). Neutrophil counts must be monitored during the first 6 months of anakinra treatment and quarterly henceforth (Swedish Orphan Biovitrum Ltd, 2007). In patients where the ANC is $<1.5 \times 10^{9} / \mathrm{L}$, treatment must be discontinued immediately (Swedish Orphan Biovitrum Ltd, 2007). The higher doses being used in COVID-19 trials and the potential for a greater $\mathrm{C}_{\max }$ due to intravenous administration potentially raise additional safety concerns. However, since the duration of treatment will be shorter than that used in rheumatoid arthritis, coupled with the fact that patients will be hospitalised, should enable earlier detection of any untoward events.

Anakinra is catabolised and eliminated via glomerular filtration (Swedish Orphan Biovitrum Ltd, 2007; B.-B. Yang, Baughman, \& Sullivan, 2003). Caution should be exercised and dose-adjustments may be required 
in moderate to severe renal impairment (Swedish Orphan Biovitrum Ltd, 2007; B.-B. Yang et al., 2003). During general infections and inflammatory diseases, CYP enzymes are primarily down-regulated (Mallick, Taneja, Moorthy, \& Ghose, 2017). Similar to IL-6 inhibitors, it may be possible that anakinra treatment restores CYP levels in infected patients (Swedish Orphan Biovitrum Ltd, 2007). Therefore, caution should be exerted in COVID-19 patients receiving concomitant medications with a narrow therapeutic window drug. Mild interactions can occur between anakinra and warfarin, clopidogrel, clozapine and phenytoin (Group, 2020).

\subsection{JAK Inhibitors}

Baricitinib is an oral disease-modifying anti-rheumatic drug (DMARD), traditionally used in the treatment of moderate to severe active rheumatoid arthritis (Al-Salama \& Scott, 2018). By acting as an ATP-competitive kinase inhibitor, baricitinib can selectively and potently inhibit janus kinases (JAKs) 1 and 2 in a reversible manner. JAKs are essential in the transduction of intracellular signals for various cytokines involved in the inflammatory and immune responses, and so by inhibiting these kinases, baricitinib is able to relieve symptoms of rheumatoid arthritis for many patients (Fridman et al., 2010).

As described previously, a common characteristic of COVID-19, much like another beta-coronavirus disease SARS, is a profuse inflammatory response (Huang et al., 2020; Stebbing et al., 2020). Increased levels of proinflammatory cytokines, such as interferon (IFN) $-\gamma$ and IL-1 $\beta$, have been observed in confirmed COVID-19 cases (Huang et al., 2020; Mehta, McAuley, et al., 2020; Russell et al., 2020). Furthermore, the levels of some specific cytokines appear to be related to disease severity; patients requiring admission to intensive care units show increased levels of $\mathrm{TNF} \alpha$ and monocyte chemoattractant protein 1 (MCP1). The rationale behind repurposing baricitinib as a treatment for COVID-19 is centred on this potential for severely ill patients to present with a cytokine storm (Mehta, McAuley, et al., 2020; Russell et al., 2020). By dampening the inflammatory response, it is postulated that baricitinib will be able to relieve COVID-19 symptoms. Data modelled using artificial intelligence techniques suggests baricitinib may work by inhibiting virus entry into cells via an endocytic regulator known to be involved in coronavirus internalisation, AP2-associated protein kinase 1 (AAK1) (Burkard et al., 2014; Richardson et al., 2020). Baricitinib, as well as being capable of JAK1 and JAK2 inhibition, is a high-affinity inhibitor of AAK1 (Richardson et al., 2020).

Patients tend to tolerate baricitinib well, and it has a relatively good safety profile (Keystone et al., 2015). However, as with tocilizumab and sarilumab treatment, a very common ([?] 1/10) AE observed in patients taking baricitinib, but not in the placebo arm, is upper respiratory tract infection, which may be related to its ability to suppress the immune system (Eli Lilly, 2017). Patients taking baricitinib have the potential to develop respiratory tract infections which may make it difficult to distinguish whether any deterioration is due to COVID-19 or a secondary infection. Other opportunistic infections including herpes zoster and urinary tract infections were also more common in the treated arm compared to placebo, and dose reduction is recommended for patients with a history of chronic infections (Eli Lilly, 2017; Josef S. Smolen et al., 2018). Secondary infections are not uncommon in severe COVID-19 patients and so the use of a drug that may make patients increasingly prone to infections will depend on the harm-benefit ratio for severe cases of COVID-19 (World Health Organisation, 2020a).

Baricitinib is currently still being trialled in patients with COVID-19 with a therapeutic dose of 2-4 mg once daily which is the same as the recommended dosage for the treatment of rheumatoid arthritis (Cantini et al., 2020; Richardson et al., 2020). There have been a small number of reports from patients taking this recommended dosage for the treatment of rheumatoid arthritis presenting with deep vein thrombosis (DVT), which was severe in some of these cases (Taylor et al., 2019). This is a cause for concern as there are increasing reports of COVID-19 patients, especially those who are critically ill and in the ICU, with thrombotic complications including pulmonary embolism and other venous and arterial thrombotic events (Klok et al., 2020; Middeldorp et al.). As baricitinib has been reported to cause DVT, there is the potential for disease-drug interactions with COVID-19 patients taking baricitinib potentially more likely to develop thrombotic complications. In order to mitigate this risk, alternative JAK inhibitors, which have a lower risk of thrombotic events, such as ruxolitinib, may be considered in the context of COVID-19 (Alvarez-Larran 
et al., 2018). However, unlike baricitinib, ruxolitinib is primarily metabolised by CYP3A4 (L. P. H. Yang \& Keating, 2012). This means that prescribing ruxolitinib instead of baricitinib may increase the risk of CYP3A4-related DDIs (Ogu \& Maxa, 2000). Baricitinib is not predicted to be involved in any problematic DDIs. Coadministration with both CYP3A inhibitors (fluconazole) and inducers (rifampicin) failed to result in any clinically relevant changes to baricitinib exposure (Eli Lilly, 2017).

Emerging reports have revealed that patients with COVID-19 experience renal impairment, which could be attributed ACE2 receptor expression on kidney endothelial cells (Varga et al., 2020). Baricitinib should not be given to patients with renal impairment as the majority of the drug is cleared through the kidneys, and monitoring of renal function will be important to prevent AEs related to over-exposure to baricitinib in those with deteriorating renal function (Eli Lilly, 2017).

\section{Stimulation of the body's anti-viral response}

\section{$5.1 I \Phi N-\beta$}

Type 1 IFNs are a group of cytokines produced during viral infection. Notably, IFN- $\beta-1$ a has a leading role in activating genes involved in immunomodulation, suppressing the inflammatory response and antiviral effects (Sallard, Lescure, Yazdanpanah, Mentre, \& Peiffer-Smadja, 2020). Whilst a variety of type 1 IFNs exist, in vitro evidence has shown that IFN- $\beta-1 \mathrm{a}$ and IFN- $\beta-1 \mathrm{~b}$ are the most potent in the inhibition of SARS-CoV and MERS-CoV (Chan et al., 2013; Hensley et al., 2004). Within the lungs, IFN- $\beta-1$ has been shown to upregulate levels of the enzyme cluster of differentiation 73 (CD73), which inhibits vascular leakage, increases the secretion of anti-inflammatory adenosine and preserves pulmonary endothelial barrier function (Kiss et al., 2007; Sallard et al., 2020). However, in vivo research has revealed that timing of administration of IFN- $\beta-1$ is imperative for positive effects. When administered shortly after MERS-CoV infection, IFN- $\beta-1$ protected mice from lethal infection, whereas delayed administration failed to effectively inhibit viral replication or pro-inflammatory cytokines, leading to fatal pneumonia (Channappanavar et al., 2019). Interestingly, in vitro evidence has revealed that SARS-CoV-2 is more sensitive to IFN- $\beta-1$ treatment than MERS-CoV and SARS-CoV, and thus supports the tenet that treatment with IFN- $\beta-1$ may be beneficial for COVID-19 patients (Lokugamage, Schindewolf, \& Menachery, 2020; Sheahan, Sims, Leist, Schäfer, et al., 2020; Thiel \& Weber, 2008). It is assumed that treatment of COVID-19 patients with IFN- $\beta-1$ will strengthen the host immune response and prevent the worsening of severe respiratory tract manifestations.

IFN- $\beta-1$ therapy has been used for the long-term management of multiple sclerosis (MS) and has been associated with a number of AEs. When administered subcutaneously in MS patients, the most common AEs were flu-like symptoms, injection site reactions, worsening of MS symptoms, menstrual disorders, mood alterations and laboratory abnormalities (Walther \& Hohlfeld, 1999). The most common laboratory abnormalities were neutropenia, leukopenia, lymphopenia and raised aminotransferases (Walther \& Hohlfeld, 1999). A genome-wide association study of patients with IFN- $\beta$ induced liver injury showed that rs 2205986 which has been linked to differential expression of interferon regulatory factor (IRF)-6 is a predisposing factor (Kowalec et al., 2018). This may be related to the fact that IRF6 leads to apoptosis in the presence of IFN- $\beta$. Depression is a common AE reported in patients receiving subcutaneous IFN- $\beta-1$ therapy, and thus caution is needed when administering to those with a previous or current history of depressive disorder (Biogen). Whilst rare, careful monitoring of clinical manifestations such as new onset hypertension, thrombocytopenia, impaired renal function and fever are required in order to identify cases of thrombotic microangiopathy (TMA) (Biogen). TMA is rare and has been reported at different time points of IFN- $\beta-1$ therapy (Biogen; Nishio et al., 2016; Yam, Fok, McLean, Butler, \& Kempster, 2018). Laboratory findings of a decreased platelet count, increased serum lactate dehydrogenase (LDH) and red blood cell fragmentation are suggestive of TMA (Biogen). If diagnosed, patients must discontinue IFN- $\beta-1$ therapy and will require plasma exchange (Biogen).

SNG001 is an inhaled form of IFN- $\beta$-1a produced by Synairgen. The company have tested the efficacy and safety of the drug for the prevention and treatment of symptoms associated with respiratory viral infection in asthma and chronic obstructive pulmonary disease (COPD) (Synairgen plc, 2018). A randomised, placebo- 
controlled phase 2 trial is currently ongoing to assess the safety and efficacy of inhaled SNG001 for the treatment of patients with COVID-19 (NCT04385095). Data from the asthma trials have revealed that when administered via inhalation, high levels of IFN- $\beta-1 \mathrm{a}$ are achieved within the lungs with lower levels within the circulation leading to improvements in lung function, antiviral responses and better asthma control (Djukanović et al., 2014). Inhaled SNG001 seems to have a good safety profile; 5 patients within the SNG001 arm reported cardiac palpitations whereas no cases were reported in the placebo arm, but symptoms were mild and not considered clinically significant (Djukanović et al., 2014).

A clinical trial has been undertaken in hospitalised COVID-19 patients where the triple combination of IFN- $\beta$, lopinavir-ritonavir and ribavirin was compared to lopinavir-ritonavir and ribavirin (Hung et al., 2020; Shalhoub, 2020). Patients in the triple combination therapy arm achieved negative COVID-19 tests results faster than those in the control arm, with improved patient symptoms, decreased viral shedding and decreased overall length of stay in the hospital compared to those in the control group (Hung et al., 2020). AEs reported in both groups included nausea and diarrhoea. However, due to poly-pharmacy in this trial, it was difficult to determine the effect of IFN- $\beta$ on SARS-CoV-2 alone.

IFN- $\beta$ has reported DDIs with other COVID-19 therapies including chloroquine and hyrdroxychloroquine, and with anakinra, sarilumab and tocilizumab (Group, 2020). DDIs have also been reported with metamizole (analgesic), linezolid (antibacterial), clozapine (antipsychotic), zidovudine (HIV antiretroviral therapy) and some immunosuppressants (adalimumab, azathioprine and pirfenidone) (Group, 2020).

Table 1: Overview of safety concerns to considered drugs for the treatment of COVID-19.

\begin{tabular}{|c|c|c|c|c|c|c|c|c|}
\hline $\begin{array}{l}\text { Drug } \\
\text { class }\end{array}$ & $\begin{array}{l}\text { Drug } \\
\text { name }\end{array}$ & Mechanism & $\begin{array}{l}\text { ADR- } \\
\text { systemic } \\
\text { symp- } \\
\text { toms, } \\
\text { miscel- } \\
\text { laneous }\end{array}$ & $\begin{array}{l}\text { ADR- } \\
\text { Organ } \\
\text { system } \\
\text { af- } \\
\text { fected }\end{array}$ & $\begin{array}{l}\text { ADR- } \\
\text { Organ } \\
\text { system } \\
\text { af- } \\
\text { fected }\end{array}$ & $\begin{array}{l}\text { ADR- } \\
\text { Organ } \\
\text { system } \\
\text { af- } \\
\text { fected }\end{array}$ & $\begin{array}{l}\text { ADR- } \\
\text { Organ } \\
\text { system } \\
\text { af- } \\
\text { fected }\end{array}$ & $\begin{array}{l}\text { ADR- } \\
\text { Organ } \\
\text { systen } \\
\text { af- } \\
\text { fected }\end{array}$ \\
\hline & & & & Lung & \multicolumn{2}{|c|}{ Gastrointestihialer } & $\begin{array}{l}\text { Kidney } \\
\& \\
\text { urinary } \\
\text { tract }\end{array}$ & Cardi \\
\hline $\begin{array}{l}\text { Angiotensin } \\
\text { receptor } \\
\text { blockers }\end{array}$ & Losartan & $\begin{array}{l}\text { Inhibitors } \\
\text { of } \\
\text { Epithelium } \\
\text { Cell Entry }\end{array}$ & $\begin{array}{l}\text { Headache, } \\
\text { dizziness, } \\
\text { hypoten- } \\
\text { sion, } \\
\text { fatigue, } \\
\text { foetal } \\
\text { toxicity }\end{array}$ & Yes? & & $\begin{array}{l}\text { ALT } \\
\text { elevation, } \\
\text { hepatotoxicity }\end{array}$ & & $\begin{array}{l}\text { Myoca } \\
\text { injury, } \\
\text { Atrial } \\
\text { fibrilla }\end{array}$ \\
\hline $\begin{array}{l}\text { Anti-HIV } \\
\text { drug } \\
\text { Protease } \\
\text { inhibitor }\end{array}$ & $\begin{array}{l}\text { Lopinavir- } \\
\text { ritonavir }\end{array}$ & $\begin{array}{l}\text { Antiviral } \\
\text { drug }\end{array}$ & & & $\begin{array}{l}\text { Diarrhoea, } \\
\text { nausea } \\
\text { vomiting, } \\
\text { pancreatitis }\end{array}$ & & & \\
\hline Antimalarial & Chloroquine & $\begin{array}{l}\text { Anytdrioxlychl } \\
\text { and im- } \\
\text { munomod- } \\
\text { ulating } \\
\text { effects }\end{array}$ & $\begin{array}{l}\text { oRotiuaihe } \\
\text { toxicity }\end{array}$ & & Yes & Yes & Yes & $\begin{array}{l}\text { QT } \\
\text { prolon- } \\
\text { gation, } \\
\text { ventric } \\
\text { ular } \\
\text { tachyce }\end{array}$ \\
\hline
\end{tabular}




\begin{tabular}{|c|c|c|c|c|c|c|c|c|}
\hline $\begin{array}{l}\text { Drug } \\
\text { class }\end{array}$ & $\begin{array}{l}\text { Drug } \\
\text { name }\end{array}$ & Mechanism & $\begin{array}{l}\text { ADR- } \\
\text { systemic } \\
\text { symp- } \\
\text { toms, } \\
\text { miscel- } \\
\text { laneous }\end{array}$ & $\begin{array}{l}\text { ADR- } \\
\text { Organ } \\
\text { system } \\
\text { af- } \\
\text { fected }\end{array}$ & $\begin{array}{l}\text { ADR- } \\
\text { Organ } \\
\text { system } \\
\text { af- } \\
\text { fected }\end{array}$ & $\begin{array}{l}\text { ADR- } \\
\text { Organ } \\
\text { system } \\
\text { af- } \\
\text { fected }\end{array}$ & $\begin{array}{l}\text { ADR- } \\
\text { Organ } \\
\text { system } \\
\text { af- } \\
\text { fected }\end{array}$ & $\begin{array}{l}\text { ADR- } \\
\text { Organ } \\
\text { system } \\
\text { af- } \\
\text { fected }\end{array}$ \\
\hline $\begin{array}{l}\text { C- } \\
\text { adenosine } \\
\text { nu- } \\
\text { cleotide } \\
\text { ana- } \\
\text { logue } \\
\text { devel- } \\
\text { oped for } \\
\text { Ebola } \\
\text { treatment }\end{array}$ & Remdesivir & $\begin{array}{l}\text { Broad } \\
\text { spec- } \\
\text { trum } \\
\text { antiviral }\end{array}$ & & Yes? & & $\begin{array}{l}\text { Mild to } \\
\text { moder- } \\
\text { ate ALT } \\
\text { and } \\
\text { AST el- } \\
\text { evation, } \\
\text { LFT } \\
\text { moni- } \\
\text { toring } \\
\text { required }\end{array}$ & $\begin{array}{l}\text { Kidney } \\
\text { toxicity }\end{array}$ & \\
\hline $\begin{array}{l}\text { Pseudo } \\
\text { purine } \\
\text { nucleotide }\end{array}$ & Favipiravir & $\begin{array}{l}\text { Broad } \\
\text { spec- } \\
\text { trum } \\
\text { antiviral }\end{array}$ & $\begin{array}{l}\text { Teratogenicity } \\
\text { embryotoxicity }\end{array}$ & $\begin{array}{l}\text { y,Bronchitis, } \\
\text { ycough }\end{array}$ & & $\begin{array}{l}\text { DILI } \\
\text { with } \\
\text { con- } \\
\text { comi- } \\
\text { tant } \\
\text { medications }\end{array}$ & & $\begin{array}{l}\text { Throml } \\
\text { with } \\
\text { oestrog }\end{array}$ \\
\hline $\begin{array}{l}\text { IL-6 } \\
\text { receptor } \\
\text { inhibitors }\end{array}$ & $\begin{array}{l}\text { Tocilizumab } \\
\text { sar- } \\
\text { ilumab, } \\
\text { siltux- } \\
\text { imab }\end{array}$ & $\begin{array}{l}\text { Modulation } \\
\text { of the } \\
\text { hyperin- } \\
\text { flammatory } \\
\text { phase, Anti } \\
\text { IL-6 } \\
\text { receptor } \\
\text { monoclonal } \\
\text { antibody }\end{array}$ & $\begin{array}{l}\text { Neutropenia, } \\
\text { increased } \\
\text { infection } \\
\text { rate, TB } \\
\text { and herpes }\end{array}$ & $\begin{array}{l}\text { Respiratory } \\
\text { infection }\end{array}$ & $\begin{array}{l}\text { Abdominal } \\
\text { pain, } \\
\text { mouth } \\
\text { ulceration, } \\
\text { nausea, } \\
\text { lipid } \\
\text { elevation, } \\
\text { vomiting } \\
\text { diarrhoea, } \\
\text { loss of } \\
\text { appetite }\end{array}$ & $\begin{array}{l}\text { Hepatotoxici } \\
\text { LFT } \\
\text { monitoring } \\
\text { required }\end{array}$ & $\begin{array}{l}\text { y,Urinary } \\
\text { tract } \\
\text { infection }\end{array}$ & \\
\hline $\begin{array}{l}\text { IL-1 } \\
\text { receptor } \\
\text { inhibitors }\end{array}$ & Anakinra & $\begin{array}{l}\text { Modulation } \\
\text { of the } \\
\text { hyperin- } \\
\text { flamma- } \\
\text { tory } \\
\text { phase, } \\
\text { IL-1 } \\
\text { receptor } \\
\text { antagonist }\end{array}$ & $\begin{array}{l}\text { infection, } \\
\text { neu- } \\
\text { trope- } \\
\text { nia, } \\
\text { throm- } \\
\text { bocy- } \\
\text { topenia, } \\
\text { headache, } \\
\text { blood } \\
\text { choles- } \\
\text { terol } \\
\text { increase } \\
\text { and } \\
\text { injection } \\
\text { site } \\
\text { reactions }\end{array}$ & $\begin{array}{l}\text { Upper } \\
\text { respira- } \\
\text { tory } \\
\text { infec- } \\
\text { tion, } \\
\text { bronchitis }\end{array}$ & & & $\begin{array}{l}\text { Urinary } \\
\text { tract } \\
\text { infection }\end{array}$ & \\
\hline
\end{tabular}




\begin{tabular}{|c|c|c|c|c|c|c|c|c|}
\hline $\begin{array}{l}\text { Drug } \\
\text { class }\end{array}$ & $\begin{array}{l}\text { Drug } \\
\text { name }\end{array}$ & Mechanism & $\begin{array}{l}\text { ADR- } \\
\text { systemic } \\
\text { symp- } \\
\text { toms, } \\
\text { miscel- } \\
\text { laneous }\end{array}$ & $\begin{array}{l}\text { ADR- } \\
\text { Organ } \\
\text { system } \\
\text { af- } \\
\text { fected }\end{array}$ & $\begin{array}{l}\text { ADR- } \\
\text { Organ } \\
\text { system } \\
\text { af- } \\
\text { fected }\end{array}$ & $\begin{array}{l}\text { ADR- } \\
\text { Organ } \\
\text { system } \\
\text { af- } \\
\text { fected }\end{array}$ & $\begin{array}{l}\text { ADR- } \\
\text { Organ } \\
\text { system } \\
\text { af- } \\
\text { fected }\end{array}$ & $\begin{array}{l}\text { ADR- } \\
\text { Organ } \\
\text { systen } \\
\text { af- } \\
\text { fected }\end{array}$ \\
\hline $\begin{array}{l}\text { JAK } \\
\text { inhibitors }\end{array}$ & Baricitinib & $\begin{array}{l}\text { Inhibition } \\
\text { of virus } \\
\text { entry } \\
\text { into } \\
\text { cells, } \\
\text { anti- } \\
\text { inflammatory } \\
\text { effect }\end{array}$ & $\begin{array}{l}\text { Deep } \\
\text { vein } \\
\text { thrombosis }\end{array}$ & & & & $\begin{array}{l}\text { Exacerbation } \\
\text { of renal } \\
\text { impairment? }\end{array}$ & \\
\hline Type 1 IFN & IFN-beta & $\begin{array}{l}\text { Stimulation } \\
\text { of the } \\
\text { body's } \\
\text { anti-viral } \\
\text { response }\end{array}$ & $\begin{array}{l}\text { neutropenia, } \\
\text { leukopenia, } \\
\text { lymphope- } \\
\text { nia, } \\
\text { depression }\end{array}$ & & & $\begin{array}{l}\text { Elevated } \\
\text { ALT }\end{array}$ & & \\
\hline
\end{tabular}

\section{Future Outlook}

Reviewing the safety of potential COVID-19 treatments (table 1) is complex due to the fast-moving pace of research in this field. For example, chloroquine and hydroxychloroquine with or without an accompanying macrolide antibiotic, have consistently been at the forefront of COVID-19 research efforts since the outbreak began. However, the astonishing developments over a week or so have led to retraction of a highly publicised paper, and results from a post-exposure prophylaxis trial and a treatment trial (RECOVERY), both of which have shown no beneficial effect of hydroxychloroquine (Boulware et al., 2020; Horby \& Landray, 2020; Mehra, Ruschitzka, \& Patel, 2020). This highlights that the rapid rate of discoveries surrounding COVID19 therapies generates the need to update this perspective frequently, in order to ensure that the safety of any newly repositioned therapies, novel developmental compounds, or new therapeutic combinations are investigated. For example, the potential use of heparin in novel forms, including nebulised therapy (clinical trial identifier NCT04397510), as an antiviral agent is currently the subject of several investigational trials. In addition, the potential utility of nitazoxanide is currently the subject of several clinical trials (Clinical Trials.gov, 2020a; Pepperrell, Pilkington, Owen, Wang, \& Hill, 2020; Rajoli et al., 2020).

It is clearly essential that the harm:benefit ratio of any pharmaceuticals being considered for use in the treatment of COVID-19 are thoroughly considered. This ratio changes dependent upon the disease stage and is correlated to potential mortality. For example, a higher risk may be accepted for patients in the later stage of severe disease than the same therapeutic agent administered in mild disease. This difference in harmbenefit analysis becomes even more striking when considering the use of such agents to prevent infection. As is the case for many highly contagious viruses, prevention by prophylaxis would be incredibly valuable. Some of the agents described in this review, including chloroquine and ritonavir have been suggested as potential prophylactic agents, but to date, data on efficacy have been disappointing (Rathi, Ish, Kalantri, \& Kalantri, 2020; Spinelli, Ceccarelli, Di Franco, \& Conti, 2020). Clearly, treatment duration for prophylaxis is expected to be longer than for treatment of COVID-19, and this may further alter the harm-benefit ratio, reinforcing the need for safety considerations at the outset of any clinical trials.

Similarly, the evaluation of therapy risk also applies to long-term recovery. As the current pandemic progresses, it is becoming apparent that being discharged from hospital does not necessarily mean that patients are free from COVID-19 symptoms. Large numbers of patients who have survived severe SARS-CoV-2 infection may have incurred long-term health problems, including some permanent loss of lung and kidney 
function (Foundation, 2020; Su et al., 2020; Summers, 2020). Consequently, it is probable that long-term therapies will be required for many patients to maintain, or ideally restore, normal physiological organ function. It is vital that therapies which will be used to treat patients during their long-term recovery are also undergoing evaluation for their safety, particularly as many of these agents may need to be administered over much longer periods of time than initial COVID-19 treatments.

The identification and characterisation of biomarkers of disease and safety will be invaluable in the further development and deployment of therapies for COVID-19. Disease biomarkers, for example of lung injury or the hyperinflammatory reponse, may allow the stratification of therapy in order to select the agent best suited to the stage of disease. Moreover, biomarkers should be considered to monitor patient safety in cases of known AEs. For example, the manufacturer's guidelines for remdesivir recommend daily liver function tests due to the risk of transaminase elevations (Gilead, 2020). These tests are essential, particularly with regards to COVID-19 where increased ALT levels are reported to be common amongst hospitalised patients (Bangash et al., 2020; L. Zhang et al., 2009). Looking to the future, improvements in the specificity, predictivity and reliability of drug-induced organ damage, through academic-industry partnerships such as the Biomarker Qualification Program in the Critical Path Institute in the US, and the European Innovative Medicines Initiative consortium Transbioline, will help improve clinical assessment of COVID-19 drug safety issues.

Continued enhancements in the speed, predictivity, and human translation of safety assessment for toxicity of anti-viral compounds is clearly warranted, and this may include animal models of SARS-CoV-2 as well asin vitro models, in order to assess efficacy alongside safety. Such a full understanding for individual therapies will indicate the combinations that can have the potential to provide the best synergy for benefit, while forewarning of the potential for increased risk/harm through pharmacokinetic or toxicodynamic interaction.

Although outside the scope of this review, a vaccine for COVID-19 remains the greatest hope to end the pandemic and protect the population. As of $6^{\text {th }}$ June 2020, according to WHO there are 10 vaccines in clinical trial stages and 123 in preclinical stages of evaluation (World Health Organisation, 2020b). Currently, potential vaccines are only just beginning to be tested for efficacy in humans in early phase studies, and therefore safety data will begin to emerge as larger numbers of individuals are administered the vaccine. Safety data regarding preliminary vaccinations against SARS and MERS are limited, but the available information may be useful during the development of COVID-19 vaccines due to the similarities between the coronavirus strains (Padron-Regalado, 2020). One safety concern relevant to coronaviruses is the potential for the induction of antibody-dependent enhancement (ADE), a phenomenon which was observed in cats vaccinated against feline infectious peritonitis coronavirus, and has also been seen in patients vaccinated against Zika virus and Dengue virus (Khandia et al., 2018; Padron-Regalado, 2020; Vennema et al., 1990). ADE can occur when non-neutralising antibodies bind to virus particles and increase their uptake into host cells, instead of rendering them non-infectious (Padron-Regalado, 2020; Tirado \& Yoon, 2003). This caused concern in initial SARS vaccine development, but can reportedly be avoided by using truncated versions of the viral S glycoproteins (He et al., 2004). Acknowledging safety concerns such as this, as well as the ways they can be attenuated, may be paramount in the timely development of a vaccine against COVID-19.

In conclusion, although expanding extremely rapidly, the field of therapies to treat COVID-19 remains in its infancy. Safety will continue to play a major role in therapeutic success, as apparent with recent reports of increased cardiac toxicity associated with the use of chloroquine/hydroxychloroquine in the treatment of COVID-19, despite its long history of use as an antimalarial. Above all, this review has exemplified the need to view safety concerns in the context of the individual and specific phase of disease in order to formulate a comprehensive harm-benefit balance. Importantly, an awareness of potential safety concerns will support the development of the next stage of therapy targeting prophylaxis and recovery post-COVID infection. It is imperative that safety scientists look to rise to the challenge of COVID-19 by utilising their expertise in mechanistic understanding, biomarker development and toxicokinetic modelling in order to support the development of COVID-19 therapies that can be used effectively and safely.

Conflict of Interest Statement 
AA, BKP, CBB, CEG, RLJ, RTK, SHK, SLP and XM declare that that they have no conflicts of interest. AO declares no direct conflict of interest but is Director and CSO for Tandem Nano Ltd and a co-inventor of patents relating to drug delivery of infectious disease medicines. AEC reports no direct conflict of interest but receives research funding for the support of SP and RLJ from Servier Pharmaceuticals and AstraZeneca, these are unrelated to the published work. AEC receives additional unrelated research funding from Janssen Pharmaceuticals. AO has received consultancy and /or research funding from ViiV Healthcare, Merck, AstraZeneca, Gilead, and Janssen unrelated to the current paper. DB received educational grants and/or consultancy from AbbVie, Novartis, Merck, Gilead and Viiv Healthcare outside the submitted work. MP receives research funding from various organisations including the MRC, NIHR, EU Commission and Health Education England. He has also received partnership funding for the following: MRC Clinical Pharmacology Training Scheme (co-funded by MRC and Roche, UCB, Eli Lilly and Novartis); and a PhD studentship jointly funded by EPSRC and Astra Zeneca. He has also unrestricted educational grant support for the UK Pharmacogenetics and Stratified Medicine Network from Bristol-Myers Squibb and UCB. None of the funding received is related to the current paper.

References

Abou-Auda, H. S., \& Sakr, W. (2010). Tocilizumab: A new anti-rheumatic drug. Saudi Pharm J, 18 (4), 257-259. doi:10.1016/j.jsps.2010.07.009

Adalja, A., \& Inglesby, T. (2019). Broad-Spectrum Antiviral Agents: A Crucial Pandemic Tool. Expert Review of Anti-infective Therapy, 17 (7), 467-470. doi:10.1080/14787210.2019.1635009

Agostini, M. L., Andres, E. L., Sims, A. C., Graham, R. L., Sheahan, T. P., Lu, X., . . . Denison, M. R. (2018). Coronavirus Susceptibility to the Antiviral Remdesivir (GS-5734) Is Mediated by the Viral Polymerase and the Proofreading Exoribonuclease. mBio, 9 (2). doi:10.1128/mBio.00221-18

Al-Salama, Z. T., \& Scott, L. J. (2018). Baricitinib: A Review in Rheumatoid Arthritis. Drugs, 78 (7), 761-772. doi:10.1007/s40265-018-0908-4

Alvarez-Larran, A., Verstovsek, S., Perez-Encinas, M., Kiladjian, J., Ferrer-Marin, F., Vannucchi, A., . . . Hernandez-Boluda, J. (2018). Comparison of ruxolitinib and real-world best available therapy in terms of overall survial and thrombosis in patients with polycythemia vera who are resistant or intolerant to hydroxyurea [Poster]. European Haematology Association.

Anger, F., Wiegering, A., Wagner, J., Lock, J., Baur, J., Haug, L., . . . Klein, I. (2017). Toxic druginduced liver failure during therapy of rheumatoid arthritis with tocilizumab subcutaneously: a case report.Rheumatology, 56 (9), 1628-1629. doi:10.1093/rheumatology/kex221

Arshad, U., Pertinez, H., Box, H., Tatham, L., Rajoli, R. K., Curley, P., . . . Owen, A. (2020). Prioritisation of potential anti-SARS-CoV-2 drug repurposing opportunities based on ability to achieve adequate target site concentrations derived from their established human pharmacokinetics. medRxiv , 2020.2004.2016.20068379. doi:10.1101/2020.04.16.20068379

Asrani, S. K., Devarbhavi, H., Eaton, J., \& Kamath, P. S. (2019). Burden of liver diseases in the world. Journal of Hepatology, 70 (1), 151-171. doi:https://doi.org/10.1016/j.jhep.2018.09.014

Atallah, B., Mallah, S. I., \& AlMahmeed, W. (2020). Anticoagulation in COVID-19. Eur Heart J Cardiovasc Pharmacother . doi:10.1093/ehjcvp/pvaa036

Bangash, M. N., Patel, J., \& Parekh, D. (2020). COVID-19 and the liver: little cause for concern. Lancet Gastroenterol Hepatol . doi:10.1016/s2468-1253(20)30084-4

Beigel, J. H., Tomashek, K. M., Dodd, L. E., Mehta, A. K., Zingman, B. S., Kalil, A. C., . . . Lane, H. C. (2020). Remdesivir for the Treatment of Covid-19 - Preliminary Report. New England Journal of Medicine . doi:10.1056/NEJMoa2007764 
Bessiere, F., Roccia, H., Deliniere, A., Charriere, R., Chevalier, P., Argaud, L., \& Cour, M. (2020). Assessment of QT Intervals in a Case Series of Patients With Coronavirus Disease 2019 (COVID-19) Infection Treated With Hydroxychloroquine Alone or in Combination With Azithromycin in an Intensive Care Unit. JAMA Cardiol . doi:10.1001/jamacardio.2020.1787

Biogen. (2007). SUMMARY OF PRODUCT CHARACTERISTICS - AVONEX. In.

Borba, M. G. S., Val, F. F. A., Sampaio, V. S., Alexandre, M. A. A., Melo, G. C., Brito, M., . . . Lacerda, M. V. G. (2020). Effect of High vs Low Doses of Chloroquine Diphosphate as Adjunctive Therapy for Patients Hospitalized With Severe Acute Respiratory Syndrome Coronavirus 2 (SARS-CoV-2) Infection: A Randomized Clinical Trial. JAMA Netw Open, 3 (4), e208857. doi:10.1001/jamanetworkopen.2020.8857

Boulware, D. R., Pullen, M. F., Bangdiwala, A. S., Pastick, K. A., Lofgren, S. M., Okafor, E. C., . . - Hullsiek, K. H. (2020). A Randomized Trial of Hydroxychloroquine as Postexposure Prophylaxis for Covid-19. N Engl J Med . doi:10.1056/NEJMoa2016638

Bresnihan, B., Alvaro-Gracia, J. M., Cobby, M., Doherty, M., Domljan, Z., Emery, P., . . . Musikic, P. (1998). Treatment of rheumatoid arthritis with recombinant human interleukin-1 receptor antagonist.Arthritis Rheum, 41 (12), 2196-2204. doi:10.1002/1529-0131(199812)41:12<2196::Aid-art15>3.0.Co;2-2

Burkard, C., Verheije, M. H., Wicht, O., van Kasteren, S. I., van Kuppeveld, F. J., Haagmans, B. L., . . . de Haan, C. A. (2014). Coronavirus cell entry occurs through the endo-/lysosomal pathway in a proteolysis-dependent manner. PLoS Pathog, 10 (11), e1004502. doi:10.1371/journal.ppat.1004502

Cantini, F., Niccoli, L., Matarrese, D., Nicastri, E., Stobbione, P., \& Goletti, D. (2020). Baricitinib therapy in COVID-19: A pilot study on safety and clinical impact. J Infect . doi:10.1016/j.jinf.2020.04.017

Cao, B., Wang, Y., Wen, D., Liu, W., Wang, J., Fan, G., . . . Wang, C. (2020). A Trial of LopinavirRitonavir in Adults Hospitalized with Severe Covid-19. N Engl J Med . doi:10.1056/NEJMoa2001282

Carter, S. J., Tattersall, R. S., \& Ramanan, A. V. (2018). Macrophage activation syndrome in adults: recent advances in pathophysiology, diagnosis and treatment. Rheumatology, 58 (1), 5-17. doi:10.1093/rheumatology/key006

Cavalli, G., De Luca, G., Campochiaro, C., Della-Torre, E., Ripa, M., Canetti, D., . . . Dagna, L. (2020). Interleukin-1 blockade with high-dose anakinra in patients with COVID-19, acute respiratory distress syndrome, and hyperinflammation: a retrospective cohort study. The Lancet Rheumatology, 2 (6), e325-e331. doi:https://doi.org/10.1016/S2665-9913(20)30127-2

Cawthorne, C., Prenant, C., Smigova, A., Julyan, P., Maroy, R., Herholz, K., . . . Boutin, H. (2011). Biodistribution, pharmacokinetics and metabolism of interleukin-1 receptor antagonist (IL-1RA) using [ $\left.{ }^{1} 8 \mathrm{~F}\right]$ IL1RA and PET imaging in rats. Br J Pharmacol, 162 (3), 659-672. doi:10.1111/j.1476-5381.2010.01068.x

Chan, J. F., Chan, K. H., Kao, R. Y., To, K. K., Zheng, B. J., Li, C. P., . . . Yuen, K. Y. (2013). Broad-spectrum antivirals for the emerging Middle East respiratory syndrome coronavirus. J Infect, 67 (6), 606-616. doi:10.1016/j.jinf.2013.09.029

Chandwani, A., \& Shuter, J. (2008). Lopinavir/ritonavir in the treatment of HIV-1 infection: a review. Ther Clin Risk Manag, 4 (5), 1023-1033. doi:10.2147/tcrm.s3285

Channappanavar, R., Fehr, A. R., Zheng, J., Wohlford-Lenane, C., Abrahante, J. E., Mack, M., . . . Perlman, S. (2019). IFN-I response timing relative to virus replication determines MERS coronavirus infection outcomes. J Clin Invest, 130 (9), 3625-3639. doi:10.1172/jci126363

Chatre, C., Roubille, F., Vernhet, H., Jorgensen, C., \& Pers, Y. M. (2018). Cardiac Complications Attributed to Chloroquine and Hydroxychloroquine: A Systematic Review of the Literature. Drug Saf, 41 (10), 919-931. doi:10.1007/s40264-018-0689-4 
Chu, C. M., Cheng, V. C., Hung, I. F., Wong, M. M., Chan, K. H., Chan, K. S., . . . Yuen, K. Y. (2004). Role of lopinavir/ritonavir in the treatment of SARS: initial virological and clinical findings. Thorax, 59 (3), 252-256. doi:10.1136/thorax.2003.012658

Clinical Trials.gov. (2019). Putative Investigational Therapeutics in the Treatment of Patients With Known Ebola Infection. Retrieved from https://clinicaltrials.gov/ct2/show/NCT02363322

Clinical Trials.gov. (2020a). Nitazoxanide | COVID-19. Retrieved from https: $/$ clinicaltrials.gov/ct2/results?cond=COVID-19\&term $=$ nitazoxanide\&cntry $=\&$ state $=\&$ city $=\&$ dist $=$

Clinical Trials.gov. (2020b). Recruiting, Active, not recruiting Studies covid-19. Retrieved from https://clinicaltrials.gov/ct2/results?cond=covid-19\&Search=Apply\&recrs=a\&recrs=d\&age_$\mathrm{v}=\&$ gndr $=\&$ type $=$ Intr\&rslt

Clinical Trials.gov. (2020c). SARS-CoV-2, Kineret and IL-1RA. Retrieved from https://clinicaltrials.gov/ct2/results?cond=COVID-19\&term $=$ anakinra\&cntry $=\&$ state $=\&$ city $=\&$ dist $=$

Clinical Trials.gov. (2020d). Vitamin C Infusion for the Treatment of Severe 2019-nCoV Infected Pneumonia. Retrieved from https://clinicaltrials.gov/ct2/show/NCT04264533

Cohen, S., Hurd, E., Cush, J., Schiff, M., Weinblatt, M. E., Moreland, L. W., . . . McCabe, D. (2002). Treatment of rheumatoid arthritis with anakinra, a recombinant human interleukin-1 receptor antagonist, in combination with methotrexate: results of a twenty-four-week, multicenter, randomized, double-blind, placebo-controlled trial.Arthritis Rheum, 46 (3), 614-624. doi:10.1002/art.10141

Commission on Human Medicines. (2020). Commission on Human Medicines advice on ibuprofen and coronavirus (COVID-19). Retrieved from https://www.gov.uk/government/news/commission-on-humanmedicines-advice-on-ibuprofen-and-coronavirus-covid-19

Concordia Pharmaceuticals Inc. (2017). PLAQUENIL@ - HYDROXYCHLOROQUINE SULFATE TABLETS, USP. In.

Conti, P., Ronconi, G., Caraffa, A., Gallenga, C. E., Ross, R., Frydas, I., \& Kritas, S. K. (2020). Induction of pro-inflammatory cytokines (IL-1 and IL-6) and lung inflammation by Coronavirus-19 (COVI-19 or SARSCoV-2): anti-inflammatory strategies. J Biol Regul Homeost Agents, 34 (2). doi:10.23812/conti-e

David, S., \& Hamilton, J. P. (2010). Drug-induced Liver Injury. US Gastroenterol Hepatol Rev, 6 , 73-80.

Dawes, B. E., Kalveram, B., Ikegami, T., Juelich, T., Smith, J. K., Zhang, L., . . Freiberg, A. N. (2018). Favipiravir (T-705) protects against Nipah virus infection in the hamster model. Scientific Reports, 8 (1), 7604. doi:10.1038/s41598-018-25780-3

Dayer, M. R., Taleb-Gassabi, S., \& Dayer, M. S. (2017). Lopinavir; A Potent Drug against Coronavirus Infection: Insight from Molecular Docking Study. Arch Clin Infect Dis, 12 (4), e13823. doi:10.5812/archcid.13823

Deisseroth, A., Ko, C. W., Nie, L., Zirkelbach, J. F., Zhao, L., Bullock, J., . . Pazdur, R. (2015). FDA approval: siltuximab for the treatment of patients with multicentric Castleman disease. Clin Cancer Res, 21 (5), 950-954. doi:10.1158/1078-0432.Ccr-14-1678

Di Micco, P., Russo, V., Carannante, N., Imparato, M., Rodolfi, S., Cardillo, G., \& Lodigiani, C. (2020). Clotting Factors in COVID-19: Epidemiological Association and Prognostic Values in Different Clinical Presentations in an Italian Cohort. J Clin Med, 9 (5). doi:10.3390/jcm9051371

Dinarello, C. A., Simon, A., \& van der Meer, J. W. (2012). Treating inflammation by blocking interleukin-1 in a broad spectrum of diseases. Nat Rev Drug Discov, 11 (8), 633-652. doi:10.1038/nrd3800

Djukanović, R., Harrison, T., Johnston, S. L., Gabbay, F., Wark, P., Thomson, N. C., . . Monk, P. (2014). The effect of inhaled IFN- $\beta$ on worsening of asthma symptoms caused by viral infections. A randomized trial. Am J Respir Crit Care Med, 190 (2), 145-154. doi:10.1164/rccm.201312-2235OC 
Dohme, M. S. (2003). SUMMARIES OF PRODUCT CHARACTERISTICS - Losartan. In.

Drepper, M., Rubbia-Brandt, L., \& Spahr, L. (2013). Tocilizumab-Induced Acute Liver Injury in Adult Onset Still's Disease. Case Reports Hepatol, 2013 , 964828. doi:10.1155/2013/964828

Eli Lilly. (2017). SUMMARY OF PRODUCT CHARACTERISTICS - Baricitinib. In.

Emery, P., Keystone, E., Tony, H. P., Cantagrel, A., van Vollenhoven, R., Sanchez, A., . . . Kremer, J. (2008). IL-6 receptor inhibition with tocilizumab improves treatment outcomes in patients with rheumatoid arthritis refractory to anti-tumour necrosis factor biologicals: results from a 24-week multicentre randomised placebo-controlled trial.Ann Rheum Dis, 67 (11), 1516-1523. doi:10.1136/ard.2008.092932

Emery, P., Rondon, J., Parrino, J., Lin, Y., Pena-Rossi, C., van Hoogstraten, H., . . . Spindler, A. (2019). Safety and tolerability of subcutaneous sarilumab and intravenous tocilizumab in patients with rheumatoid arthritis. Rheumatology (Oxford), 58 (5), 849-858. doi:10.1093/rheumatology/key361

European Medicines Agency. (2020). Summary on compassionate use - Remdesivir Gilead. In.

Fang, L., Karakiulakis, G., \& Roth, M. (2020). Are patients with hypertension and diabetes mellitus at increased risk for COVID-19 infection? Lancet Respir Med . doi:10.1016/s2213-2600(20)30116-8

Favalli, E. G., Ingegnoli, F., De Lucia, O., Cincinelli, G., Cimaz, R., \& Caporali, R. (2020). COVID-19 infection and rheumatoid arthritis: Faraway, so close! Autoimmun Rev , 102523. doi:10.1016/j.autrev.2020.102523

Ferrario, C. M., Jessup, J., Chappell, M. C., Averill, D. B., Brosnihan, K. B., Tallant, E. A., . . Gallagher, P. E. (2005). Effect of angiotensin-converting enzyme inhibition and angiotensin II receptor blockers on cardiac angiotensin-converting enzyme 2. Circulation, 111 (20), 2605-2610. doi:10.1161/circulationaha.104.510461

Fleischmann, R., van Adelsberg, J., Lin, Y., Castelar-Pinheiro, G. D., Brzezicki, J., Hrycaj, P., . . . Burmester, G. R. (2017). Sarilumab and Nonbiologic Disease-Modifying Antirheumatic Drugs in Patients With Active Rheumatoid Arthritis and Inadequate Response or Intolerance to Tumor Necrosis Factor Inhibitors. Arthritis Rheumatol, 69 (2), 277-290. doi:10.1002/art.39944

Fleischmann, R. M., Halland, A. M., Brzosko, M., Burgos-Vargas, R., Mela, C., Vernon, E., \& Kremer, J. M. (2013). Tocilizumab inhibits structural joint damage and improves physical function in patients with rheumatoid arthritis and inadequate responses to methotrexate: LITHE study 2-year results. J Rheumatol, 40 (2), 113-126. doi:10.3899/jrheum. 120447

Fleischmann, R. M., Schechtman, J., Bennett, R., Handel, M. L., Burmester, G. R., Tesser, J., . . . Sun, G. (2003). Anakinra, a recombinant human interleukin-1 receptor antagonist (r-metHuIL-1ra), in patients with rheumatoid arthritis: A large, international, multicenter, placebo-controlled trial. Arthritis Rheum, 48 (4), 927-934. doi:10.1002/art.10870

Foundation, E. L. (2020). COVID-19 AND LUNG DISEASE Q\&A. .

Fridman, J. S., Scherle, P. A., Collins, R., Burn, T. C., Li, Y., Li, J., . . . Vaddi, K. (2010). Selective Inhibition of JAK1 and JAK2 Is Efficacious in Rodent Models of Arthritis: Preclinical Characterization of INCB028050. The Journal of Immunology, 184 (9), 5298-5307. doi:10.4049/jimmunol.0902819

Furuta, Y., Gowen, B. B., Takahashi, K., Shiraki, K., Smee, D. F., \& Barnard, D. L. (2013). Favipiravir (T-705), a novel viral RNA polymerase inhibitor. Antiviral Research, 100 (2), 446-454. doi:https://doi.org/10.1016/j.antiviral.2013.09.015

Furuta, Y., Komeno, T., \& Nakamura, T. (2017). Favipiravir (T-705), a broad spectrum inhibitor of viral RNA polymerase. Proceedings of the Japan Academy, Series B, 93 (7), 449-463. doi:10.2183/pjab.93.027 
Furuta, Y., Takahashi, K., Fukuda, Y., Kuno, M., Kamiyama, T., Kozaki, K., . . . Shiraki, K. (2002). In Vitro and In Vivo Activities of Anti-Influenza Virus Compound T-705. Antimicrobial Agents and Chemotherapy, 46 (4), 977-981. doi:10.1128/aac.46.4.977-981.2002

Gao, J., Tian, Z., \& Yang, X. (2020). Breakthrough: Chloroquine phosphate has shown apparent efficacy in treatment of COVID-19 associated pneumonia in clinical studies. Biosci Trends, 14 (1), 72-73. doi:10.5582/bst.2020.01047

Gautret, P., Lagier, J. C., Parola, P., Hoang, V. T., Meddeb, L., Mailhe, M., . . . Raoult, D. (2020). Hydroxychloroquine and azithromycin as a treatment of COVID-19: results of an open-label non-randomized clinical trial. Int J Antimicrob Agents , 105949. doi:10.1016/j.ijantimicag.2020.105949

Gautret, P., Lagier, J. C., Parola, P., Hoang, V. T., Meddeb, L., Sevestre, J., . . . Raoult, D. (2020). Clinical and microbiological effect of a combination of hydroxychloroquine and azithromycin in 80 COVID19 patients with at least a six-day follow up: A pilot observational study. Travel Med Infect Dis, 34, 101663. doi:10.1016/j.tmaid.2020.101663

Genovese, M. C., Fleischmann, R., Kivitz, A. J., Rell-Bakalarska, M., Martincova, R., Fiore, S., . . . van der Heijde, D. (2015). Sarilumab Plus Methotrexate in Patients With Active Rheumatoid Arthritis and Inadequate Response to Methotrexate: Results of a Phase III Study.Arthritis Rheumatol, 67 (6), 1424-1437. doi:10.1002/art.39093

Genovese, M. C., Smolen, J. S., Emery, P., Jones, G., Lee, J. S., Alecock, E., \& Kremer, J. M. (2008). Lipid and inflammatory biomarker profiles in patients receiving tocilizumab for rheumatoid arthritis: analysis of five phase 3 clinical trials. Paper presented at the Arthritis Rheum.

Genovese, M. C., van der Heijde, D., Lin, Y., St John, G., Wang, S., van Hoogstraten, H., . . . Burmester, G. R. (2019). Long-term safety and efficacy of sarilumab plus methotrexate on disease activity, physical function and radiographic progression: 5 years of sarilumab plus methotrexate treatment. RMD Open, 5 (2), e000887. doi:10.1136/rmdopen-2018-000887

Gilead. (2020). FACT SHEET FOR HEALTH CARE PROVIDERS: EMERGENCY USE AUTHORIZATION (EUA) OF REMDESIVIR (GS-5734). In.

Giner Galvan, V., Oltra, M. R., Rueda, D., Esteban, M. J., \& Redon, J. (2007). Severe acute hepatitis related to hydroxychloroquine in a woman with mixed connective tissue disease. Clin Rheumatol, 26 (6), 971-972. doi:10.1007/s10067-006-0218-1

Goa, K. L., \& Wagstaff, A. J. (1996). Losartan potassium: a review of its pharmacology, clinical efficacy and tolerability in the management of hypertension. Drugs, 51 (5), 820-845. doi:10.2165/00003495-19965105000008

Group, L. D. I. (2020). Interactions with Experimental COVID-19 Therapies. Retrieved from http://www.covid19-druginteractions.org/

Guan, W.-j., Ni, Z.-y., Hu, Y., Liang, W.-h., Ou, C.-q., He, J.-x., . . . Zhong, N.-s. (2020). Clinical Characteristics of Coronavirus Disease 2019 in China. New England Journal of Medicine, 382 (18), 17081720. doi:10.1056/NEJMoa2002032

Guo, Y. R., Cao, Q. D., Hong, Z. S., Tan, Y. Y., Chen, S. D., Jin, H. J., . . . Yan, Y. (2020). The origin, transmission and clinical therapies on coronavirus disease 2019 (COVID-19) outbreak - an update on the status. Mil Med Res, 7 (1), 11. doi:10.1186/s40779-020-00240-0

Gurwitz, D. (2020). Angiotensin receptor blockers as tentative SARS-CoV-2 therapeutics. Drug Dev Res . doi:10.1002/ddr.21656

He, Y., Zhou, Y., Liu, S., Kou, Z., Li, W., Farzan, M., \& Jiang, S. (2004). Receptor-binding domain of SARS-CoV spike protein induces highly potent neutralizing antibodies: implication for developing subunit 
vaccine. Biochem Biophys Res Commun, 324 (2), 773-781. doi:https://doi.org/10.1016/j.bbrc.2004.09.106

Hensley, L. E., Fritz, L. E., Jahrling, P. B., Karp, C. L., Huggins, J. W., \& Geisbert, T. W. (2004). Interferonbeta 1a and SARS coronavirus replication. Emerg Infect Dis, 10 (2), 317-319. doi:10.3201/eid1002.030482

Hoffmann, M., Kleine-Weber, H., Schroeder, S., Kruger, N., Herrler, T., Erichsen, S., . . . Pohlmann, S. (2020). SARS-CoV-2 Cell Entry Depends on ACE2 and TMPRSS2 and Is Blocked by a Clinically Proven Protease Inhibitor. Cell . doi:10.1016/j.cell.2020.02.052

Horby, P., \& Landray, M. (2020). Statement from the Chief Investigators of the Randomised Evaluation of COVid-19 thERapY (RECOVERY) Trial on hydroxychloroquine, 5 June 2020 [Press release]. Retrieved from https://www.recoverytrial.net/files/hcq-recovery-statement-050620-final-002.pdf

Hoshi, D., Nakajima, A., Inoue, E., Shidara, K., Sato, E., Kitahama, M., . . . Yamanaka, H. (2012). Incidence of serious respiratory infections in patients with rheumatoid arthritis treated with tocilizumab.Mod Rheumatol, 22 (1), 122-127. doi:10.1007/s10165-011-0488-6

Huang, C., Wang, Y., Li, X., Ren, L., Zhao, J., Hu, Y., . . . Cao, B. (2020). Clinical features of patients infected with 2019 novel coronavirus in Wuhan, China. The Lancet, 395 (10223), 497-506. doi:https://doi.org/10.1016/S0140-6736(20)30183-5

Huet, T., Beaussier, H., Voisin, O., Jouveshomme, S., Dauriat, G., Lazareth, I., . . . Hayem, G. (2020). Anakinra for severe forms of COVID-19: a cohort study. The Lancet Rheumatology . doi:https://doi.org/10.1016/S2665-9913(20)30164-8

Huizinga, T. W., Fleischmann, R. M., Jasson, M., Radin, A. R., van Adelsberg, J., Fiore, S., . . . Genovese, M. C. (2014). Sarilumab, a fully human monoclonal antibody against IL-6Ralpha in patients with rheumatoid arthritis and an inadequate response to methotrexate: efficacy and safety results from the randomised SARILRA-MOBILITY Part A trial. Ann Rheum Dis, 73 (9), 1626-1634. doi:10.1136/annrheumdis-2013-204405

Hung, I. F.-N., Lung, K.-C., Tso, E. Y.-K., Liu, R., Chung, T. W.-H., Chu, M.-Y., . . . Yuen, K.-Y. (2020). Triple combination of interferon beta-1b, lopinavir-ritonavir, and ribavirin in the treatment of patients admitted to hospital with COVID-19: an open-label, randomised, phase 2 trial. The Lancet, 395 (10238), 1695-1704. doi:https://doi.org/10.1016/S0140-6736(20)31042-4

Hurley, D. (2020). Sharp Increase in Large-Vessel Stroke Risk Seen In Young, Healthy COVID-19 Patients. Retrieved from https://journals.lww.com/neurotodayonline/fulltext/2020/05210/sharp_increase_in_large_vessel_stroke_risk_seen_in.2.aspx?casa_token=bfLY2Y_IXFoAAAAA:IBs0WBigfoATf249JaCH91DIMkuIWwTKP_p9ZND_7VhnzGRB4FaYjkT5mcmRZiikXvIbo5_hnTwXunlk5WMRVR5I0wTXXUzC-J2xog

Identifier ChiCTR2000029996, A randomized, open-label, controlled trial for the efficacy and safety of Farpiravir Tablets in the treatment of patients with novel coronavirus pneumonia (COVID-19). (2020). Retrieved from http://www.chictr.org.cn

Inc., A. (2001). Kineret (anakinra). In.

Inc., A. (2016). FULL PRESCRIBING INFORMATION - KALETRA In.

Janssen Biotech Inc. (2019). SUMMARY OF PRODUCT CHARACTERISTICS - Siltuximab. In.

John Hopkins University and Medicine. (2020). Coronavirus COVID-19 Global Cases by the Center for Systems Science and Engineering (CSSE) at Johns Hopkins University (JHU). Retrieved from https://coronavirus.jhu.edu/map.html

Jones, G., Sebba, A., Gu, J., Lowenstein, M. B., Calvo, A., Gomez-Reino, J. J., . . . Genovese, M. C. (2010). Comparison of tocilizumab monotherapy versus methotrexate monotherapy in patients with moderate to severe rheumatoid arthritis: the AMBITION study. Ann Rheum Dis, 69 (1), 88-96. doi:10.1136/ard.2008.105197 
Kaiser, C., Knight, A., Nordström, D., Pettersson, T., Fransson, J., Florin-Robertsson, E., \& Pilström, B. (2012). Injection-site reactions upon Kineret (anakinra) administration: experiences and explanations.Rheumatology International, 32 (2), 295-299. doi:10.1007/s00296-011-2096-3

Kameda, H., Wada, K., Takahashi, Y., Hagino, O., van Hoogstraten, H., Graham, N., \& Tanaka, Y. (2020). Sarilumab monotherapy or in combination with non-methotrexate disease-modifying antirheumatic drugs in active rheumatoid arthritis: A Japan phase 3 trial (HARUKA).Mod Rheumatol, 30 (2), 239-248. doi:10.1080/14397595.2019.1639939

Keystone, E. C., Taylor, P. C., Drescher, E., Schlichting, D. E., Beattie, S. D., Berclaz, P.-Y., . . . Genovese, M. C. (2015). Safety and efficacy of baricitinib at 24 weeks in patients with rheumatoid arthritis who have had an inadequate response to methotrexate. Annals of the Rheumatic Diseases, 74 (2), 333-340. doi:10.1136/annrheumdis-2014-206478

Khandia, R., Munjal, A., Dhama, K., Karthik, K., Tiwari, R., Malik, Y. S., . . . Chaicumpa, W. (2018). Modulation of Dengue/Zika Virus Pathogenicity by Antibody-Dependent Enhancement and Strategies to Protect Against Enhancement in Zika Virus Infection. Frontiers in immunology, 9 , 597-597. doi:10.3389/fimmu.2018.00597

Kiss, J., Yegutkin, G. G., Koskinen, K., Savunen, T., Jalkanen, S., \& Salmi, M. (2007). IFN- $\beta$ protects from vascular leakage via up-regulation of CD73. European Journal of Immunology, 37 (12), 3334-3338. doi:10.1002/eji.200737793

Klimas, J., Olvedy, M., Ochodnicka-Mackovicova, K., Kruzliak, P., Cacanyiova, S., Kristek, F., . . . Ochodnicky, P. (2015). Perinatally administered losartan augments renal ACE2 expression but not cardiac or renal Mas receptor in spontaneously hypertensive rats. J Cell Mol Med, 19 (8), 1965-1974. doi:10.1111/jcmm.12573

Klok, F. A., Kruip, M., van der Meer, N. J. M., Arbous, M. S., Gommers, D., Kant, K. M., . . . Endeman, H. (2020). Confirmation of the high cumulative incidence of thrombotic complications in critically ill ICU patients with COVID-19: An updated analysis. Thromb Res . doi:10.1016/j.thromres.2020.04.041

Kowalec, K., Wright, G. E. B., Drögemöller, B. I., Aminkeng, F., Bhavsar, A. P., Kingwell, E., . . Carleton, B. C. (2018). Common variation near IRF6 is associated with IFN- $\beta$-induced liver injury in multiple sclerosis. Nature Genetics, 50 (8), 1081-1085. doi:10.1038/s41588-018-0168-y

La Rosée, P., Horne, A., Hines, M., von Bahr Greenwood, T., Machowicz, R., Berliner, N., . . Henter, J.-I. (2019). Recommendations for the management of hemophagocytic lymphohistiocytosis in adults. Blood, 133 (23), 2465-2477. doi:10.1182/blood.2018894618

Li, Y., Xie, Z., Lin, W., Cai, W., Wen, C., Guan, Y., . . Li, L. (2020). An exploratory randomized controlled study on the efficacy and safety of lopinavir/ritonavir or arbidol treating adult patients hospitalized with mild/moderate COVID-19 (ELACOI). medRxiv , 2020.2003.2019.20038984. doi:10.1101/2020.03.19.20038984

Liu, J., Cao, R., Xu, M., Wang, X., Zhang, H., Hu, H., . . Wang, M. (2020). Hydroxychloroquine, a less toxic derivative of chloroquine, is effective in inhibiting SARS-CoV-2 infection in vitro. Cell Discov, 6 , 16. doi:10.1038/s41421-020-0156-0

Liu, T., Hu, J., Kang, M., Lin, L., Zhong, H., Xiao, J., . . Ma, W. (2020). Transmission dynamics of 2019 novel coronavirus (2019-nCoV).bioRxiv , 2020.2001.2025.919787. doi:10.1101/2020.01.25.919787

LiverTox. (2016). Clinical and Research Information on Drug-Induced Liver Injury - Siltuximab. Retrieved from https://www.ncbi.nlm.nih.gov/books/NBK548932/

LiverTox. (2017a). Clinical and Reseach Information on Drug-induced Liver Injury - Losartan. Retrieved from https://www.ncbi.nlm.nih.gov/books/NBK547842/ 
LiverTox. (2017b). Clinical and Research Information on Drug-Induced Liver Injury [Internet]. - Sarilumab. Retrieved from https://www.ncbi.nlm.nih.gov/books/NBK547964/

Lokugamage, K. G., Schindewolf, C., \& Menachery, V. D. (2020). SARS-CoV-2 sensitive to type I interferon pretreatment. bioRxiv , 2020.2003.2007.982264. doi:10.1101/2020.03.07.982264

Madelain, V., Nguyen, T. H., Olivo, A., de Lamballerie, X., Guedj, J., Taburet, A. M., \& Mentré, F. (2016). Ebola Virus Infection: Review of the Pharmacokinetic and Pharmacodynamic Properties of Drugs Considered for Testing in Human Efficacy Trials. Clin Pharmacokinet, 55 (8), 907-923. doi:10.1007/s40262-015-0364-1

Magagnoli, J., Narendran, S, Pereira, F, Cummings, F, Hardin, JW, Scott SS, Ambati, J. (2020). Outcomes of hydroxychloroquine usage in United States veterans hospitalized with Covid-19. medRxiv . doi: https://doi.org/10.1101/2020.04.16.20065920

Mahamid, M., Mader, R., \& Safadi, R. (2011). Hepatotoxicity of tocilizumab and anakinra in rheumatoid arthritis: management decisions. Clin Pharmacol, 3 , 39-43. doi:10.2147/cpaa.S24004

Maini, R. N., Taylor, P. C., Szechinski, J., Pavelka, K., Broll, J., Balint, G., . . Kishimoto, T. (2006). Double-blind randomized controlled clinical trial of the interleukin- 6 receptor antagonist, tocilizumab, in European patients with rheumatoid arthritis who had an incomplete response to methotrexate. Arthritis Rheum, 54 (9), 2817-2829. doi:10.1002/art.22033

Mallick, P., Taneja, G., Moorthy, B., \& Ghose, R. (2017). Regulation of drug-metabolizing enzymes in infectious and inflammatory disease: implications for biologics-small molecule drug interactions.Expert Opin Drug Metab Toxicol, 13 (6), 605-616. doi:10.1080/17425255.2017.1292251

Mao, R., Qiu, Y., He, J.-S., Tan, J.-Y., Li, X.-H., Liang, J., . . . Chen, M.-H. (2020). Manifestations and prognosis of gastrointestinal and liver involvement in patients with COVID-19: a systematic review and metaanalysis. The Lancet Gastroenterology $\mathscr{E}$ Hepatology . doi:https://doi.org/10.1016/S2468-1253(20)30126-6

Marmor, M. F., Kellner, U., Lai, T. Y., Lyons, J. S., Mieler, W. F., \& American Academy of, O. (2011). Revised recommendations on screening for chloroquine and hydroxychloroquine retinopathy. Ophthalmology, 118 (2), 415-422. doi:10.1016/j.ophtha.2010.11.017

Mathian, A., Mahevas, M., Rohmer, J., Roumier, M., Cohen-Aubart, F., Amador-Borrero, B., . . Amoura, Z. (2020). Clinical course of coronavirus disease 2019 (COVID-19) in a series of 17 patients with systemic lupus erythematosus under long-term treatment with hydroxychloroquine. Ann Rheum Dis . doi:10.1136/annrheumdis-2020-217566

McCarty, D., \& Robinson, A. (2018). Efficacy and safety of sarilumab in patients with active rheumatoid arthritis. Ther Adv Musculoskelet Dis, 10 (3), 61-67. doi:10.1177/1759720x17752037

McChesney, E. W., Banks, W. F., Jr., \& Fabian, R. J. (1967). Tissue distribution of chloroquine, hydroxychloroquine, and desethylchloroquine in the rat. Toxicol Appl Pharmacol, 10 (3), 501-513. doi:10.1016/0041$008 \mathrm{x}(67) 90089-0$

Medicines and healthcare products Regulatory Agency. (2020a). Coronavirus (COVID-19) and high blood pressure medication. Retrieved from https://www.gov.uk/government/news/coronavirus-covid-19-and-highblood-pressure-medication

Medicines and Healthcare products Regulatory Agency. (2020b). Early access to medicines scheme (EAMS) scientific opinion: Remdesivir in the treatment of patients hospitalised with suspected or laboratory-confirmed SARS-CoV-2 infection who meet the clinical criteria. Retrieved from https://www.gov.uk/government/publications/early-access-to-medicines-scheme-eams-scientificopinion-remdesivir-in-the-treatment-of-patients-hospitalised-with-suspected-or-laboratory-confirme

Mehra, M. R., Ruschitzka, F., \& Patel, A. N. (2020). Retraction-Hydroxychloroquine or chloroquine with or without a macrolide for treatment of COVID-19: a multinational registry analysis. The Lancet . 
doi:https://doi.org/10.1016/S0140-6736(20)31324-6

Mehta, P., Cron, R. Q., Hartwell, J., Manson, J. J., \& Tattersall, R. S. (2020). Silencing the cytokine storm: the use of intravenous anakinra in haemophagocytic lymphohistiocytosis or macrophage activation syndrome. The Lancet Rheumatology, 2 (6), e358-e367. doi:https://doi.org/10.1016/S2665-9913(20)30096-5

Mehta, P., McAuley, D. F., Brown, M., Sanchez, E., Tattersall, R. S., \& Manson, J. J. (2020). COVID19: consider cytokine storm syndromes and immunosuppression. The Lancet, 395 (10229), 1033-1034. doi:https://doi.org/10.1016/S0140-6736(20)30628-0

Mercuro, N. J., Yen, C. F., Shim, D. J., Maher, T. R., McCoy, C. M., Zimetbaum, P. J., \& Gold, H. S. (2020). Risk of QT Interval Prolongation Associated With Use of Hydroxychloroquine With or Without Concomitant Azithromycin Among Hospitalized Patients Testing Positive for Coronavirus Disease 2019 (COVID-19). JAMA Cardiol . doi:10.1001/jamacardio.2020.1834

Mertens, M., \& Singh, J. A. (2009). Anakinra for rheumatoid arthritis: a systematic review. J Rheumatol, 36 (6), 1118-1125. doi:10.3899/jrheum.090074

Michaelides, M., Stover, N. B., Francis, P. J., \& Weleber, R. G. (2011). Retinal toxicity associated with hydroxychloroquine and chloroquine: risk factors, screening, and progression despite cessation of therapy. Arch Ophthalmol, 129 (1), 30-39. doi:10.1001/archophthalmol.2010.321

Middeldorp, S., Coppens, M., van Haaps, T. F., Foppen, M., Vlaar, A. P., Müller, M. C. A., . . . van Es, N. (2020). Incidence of venous thromboembolism in hospitalized patients with COVID-19. Journal of Thrombosis and Haemostasis, n/a (n/a). doi:10.1111/jth.14888

Million, M., Lagier, J. C., Gautret, P., Colson, P., Fournier, P. E., Amrane, S., . . Raoult, D. (2020). Fulllength title: Early treatment of COVID-19 patients with hydroxychloroquine and azithromycin: A retrospective analysis of 1061 cases in Marseille, France. Travel Med Infect Dis , 101738. doi:10.1016/j.tmaid.2020.101738

Mittal, L., Zhang, L., Feng, R., \& Werth, V. P. (2018). Antimalarial drug toxicities in patients with cutaneous lupus and dermatomyositis: A retrospective cohort study. J Am Acad Dermatol, 78 (1), 100-106 e101. doi:10.1016/j.jaad.2017.09.061

Mullard, A. (2018). Ebola outbreak prompts experimental drug rollout.Nat Rev Drug Discov, 17 (7), 460. doi:10.1038/nrd.2018.114

National Institute for Health and Care Excellence. (2020a). ANAKINRA. Retrieved from https://bnf.nice.org.uk/drug/anakinra.html

National Institute for Health and Care Excellence. (2020b). SILTUXIMAB. Retrieved from https://bnf.nice.org.uk/drug/siltuximab.html\#monitoringRequirements

National Institute for Health and Care Excellence. (2020c). TOCILIZUMAB. Retrieved from https://bnf.nice.org.uk/drug/tocilizumab.html

Nayar, B., Singhal, A., Aggarwal, R., \& Malhotra, N. (2003). Losartan induced fetal toxicity. Indian $J$ Pediatr, 70 (11), 923-924. doi:10.1007/bf02730601

NHS. (2019). What if I take an extra contraceptive pill by accident? Retrieved from https://www.nhs.uk/conditions/contraception/taken-extra-pill-by-accident/

Nishimoto, N., Miyasaka, N., Yamamoto, K., Kawai, S., Takeuchi, T., \& Azuma, J. (2009). Long-term safety and efficacy of tocilizumab, an anti-IL-6 receptor monoclonal antibody, in monotherapy, in patients with rheumatoid arthritis (the STREAM study): evidence of safety and efficacy in a 5-year extension study. Ann Rheum Dis, 68 (10), 1580-1584. doi:10.1136/ard.2008.092866

Nishio, H., Tsukamoto, T., Matsubara, T., Okada, Y., Takahashi, R., \& Yanagita, M. (2016). Thrombotic microangiopathy caused by interferon $\beta-1 b$ for multiple sclerosis: a case report. CEN Case Rep, 5 (2), 
179-183. doi:10.1007/s13730-016-0220-7

Ogu, C. C., \& Maxa, J. L. (2000). Drug interactions due to cytochrome P450. Proc (Bayl Univ Med Cent), 13 (4), 421-423. doi:10.1080/08998280.2000.11927719

Ohkuma, S., \& Poole, B. (1981). Cytoplasmic vacuolation of mouse peritoneal macrophages and the uptake into lysosomes of weakly basic substances. J Cell Biol, 90 (3), 656-664. doi:10.1083/jcb.90.3.656

Oldfield, V., \& Plosker, G. L. (2006). Lopinavir/ritonavir: a review of its use in the management of HIV infection. Drugs, 66 (9), 1275-1299. doi:10.2165/00003495-200666090-00012

Padron-Regalado, E. (2020). Vaccines for SARS-CoV-2: Lessons from Other Coronavirus Strains. Infectious Diseases and Therapy, 9 (2), 255-274. doi:10.1007/s40121-020-00300-x

Palacios, R., Vergara, S., Rivero, A., Aguilar, I., Macías, J., Camacho, A., . . S Santos, J. (2006). Low incidence of severe liver events in HIV patients with and without hepatitis C or B coinfection receiving lopinavir/ritonavir. HIV Clin Trials, 7 (6), 319-323. doi:10.1310/hct0706-319

Pavlicević, I., Kuzmanić, M., Rumboldt, M., \& Rumboldt, Z. (2008). Interaction between antihypertensives and NSAIDs in primary care: a controlled trial. Can J Clin Pharmacol, 15 (3), e372-382.

Pawar, A., Desai, R. J., Solomon, D. H., Santiago Ortiz, A. J., Gale, S., Bao, M., . . . Kim, S. C. (2019). Risk of serious infections in tocilizumab versus other biologic drugs in patients with rheumatoid arthritis: a multidatabase cohort study. Ann Rheum Dis, 78 (4), 456-464. doi:10.1136/annrheumdis-2018-214367

Pepperrell, T., Pilkington, V., Owen, A., Wang, J., \& Hill, A. M. (2020). Review of safety and minimum pricing of nitazoxanide for potential treatment of COVID-19. J Virus Erad, 6 (2), 52-60.

Pilkington, V., Pepperrell, T., \& Hill, A. (2020). A review of the safety of favipiravir - a potential treatment in the COVID-19 pandemic? J Virus Erad, 6 (2), 45-51.

PMDA. (2014). Report on the Deliberation Results . Retrieved from https://www.pmda.go.jp/files/000210319.pdf

Prevention, C. f. $\quad$ D. C. a. (2019). Contraceptive Use. Retrieved from https://www.cdc.gov/nchs/fastats/contraceptive.htm

Qi, F., Qian, S., Zhang, S., \& Zhang, Z. (2020). Single cell RNA sequencing of 13 human tissues identify cell types and receptors of human coronaviruses. Biochem Biophys Res Commun, 526 (1), 135-140. doi:10.1016/j.bbrc.2020.03.044

Rajoli, R. K., Pertinez, H., Arshad, U., Box, H., Tatham, L., Curley, P., . . . Owen, A. (2020). Dose prediction for repurposing nitazoxanide in SARS-CoV-2 treatment or chemoprophylaxis. medRxiv , 2020.2005.2001.20087130. doi:10.1101/2020.05.01.20087130

Rathi, S., Ish, P., Kalantri, A., \& Kalantri, S. (2020). Hydroxychloroquine prophylaxis for COVID-19 contacts in India. The Lancet Infectious Diseases . doi:10.1016/S1473-3099(20)30313-3

Rebecca, V. W., Nicastri, M. C., Fennelly, C., Chude, C. I., Barber-Rotenberg, J. S., Ronghe, A., . . . Amaravadi, R. K. (2019). PPT1 Promotes Tumor Growth and Is the Molecular Target of Chloroquine Derivatives in Cancer. Cancer Discov, 9 (2), 220-229. doi:10.1158/2159-8290.CD-18-0706

Richardson, P., Griffin, I., Tucker, C., Smith, D., Oechsle, O., Phelan, A., \& Stebbing, J. (2020). Baricitinib as potential treatment for 2019-nCoV acute respiratory disease. The Lancet, 395 (10223), e30-e31. doi:https://doi.org/10.1016/S0140-6736(20)30304-4

Ripley, E., \& Hirsch, A. (2010). Fifteen years of losartan: what have we learned about losartan that can benefit chronic kidney disease patients? Int J Nephrol Renovasc Dis, 3 , 93-98. doi:10.2147/ijnrd.s7038

Roche Pharma. (2013). SUMMARY OF PRODUCT CHARACTERISTICS - Tocilizumab. 
Rodriguez-Menchaca, A. A., Navarro-Polanco, R. A., Ferrer-Villada, T., Rupp, J., Sachse, F. B., TristaniFirouzi, M., \& Sanchez-Chapula, J. A. (2008). The molecular basis of chloroquine block of the inward rectifier Kir2.1 channel. Proc Natl Acad Sci U S A, 105 (4), 1364-1368. doi:10.1073/pnas.0708153105

Ronco, C., Reis, T., \& Husain-Syed, F. (2020). Management of acute kidney injury in patients with COVID19. The Lancet Respiratory Medicine . doi:https://doi.org/10.1016/S2213-2600(20)30229-0

Russell, B., Moss, C., George, G., Santaolalla, A., Cope, A., Papa, S., \& Van Hemelrijck, M. (2020). Associations between immune-suppressive and stimulating drugs and novel COVID-19 - a systematic review of current evidence. ecancermedicalscience, 14 , 1022. doi:10.3332/ecancer.2020.1022

Sallard, E., Lescure, F. X., Yazdanpanah, Y., Mentre, F., \& Peiffer-Smadja, N. (2020). Type 1 interferons as a potential treatment against COVID-19. Antiviral Res, 178 , 104791. doi:10.1016/j.antiviral.2020.104791

Salvana, E. M., \& Salata, R. A. (2009). Infectious complications associated with monoclonal antibodies and related small molecules. Clin Microbiol Rev, 22 (2), 274-290, Table of Contents. doi:10.1128/cmr.00040-08

Sangawa, H., Komeno, T., Nishikawa, H., Yoshida, A., Takahashi, K., Nomura, N., \& Furuta, Y. (2013). Mechanism of Action of T-705 Ribosyl Triphosphate against Influenza Virus RNA Polymerase. Antimicrobial Agents and Chemotherapy, 57 (11), 5202-5208. doi:10.1128/aac.00649-13

Sanofi-Aventis. (2017). SUMMARY OF PRODUCT CHARACTERISTICS - Sarilumab.

Sanofi-Aventis. (2017 ). ARALEN@ - CHLOROQUINE PHOSPHATE, USP In.

Savarino, A., Boelaert, J. R., Cassone, A., Majori, G., \& Cauda, R. (2003). Effects of chloroquine on viral infections: an old drug against today's diseases? Lancet Infect Dis, 3 (11), 722-727. doi:10.1016/s14733099(03)00806-5

Savarino, A., Lucia, M. B., Rastrelli, E., Rutella, S., Golotta, C., Morra, E., . . Cauda, R. (2004). Anti-HIV effects of chloroquine: inhibition of viral particle glycosylation and synergism with protease inhibitors. $J$ Acquir Immune Defic Syndr, 35 (3), 223-232. doi:10.1097/00126334-200403010-00002

Schrezenmeier, E., \& Dorner, T. (2020). Mechanisms of action of hydroxychloroquine and chloroquine: implications for rheumatology.Nat Rev Rheumatol, 16 (3), 155-166. doi:10.1038/s41584-020-0372-x

Seguin, A., Galicier, L., Boutboul, D., Lemiale, V., \& Azoulay, E. (2016). Pulmonary Involvement in Patients With Hemophagocytic Lymphohistiocytosis. Chest, 149 (5), 1294-1301. doi:10.1016/j.chest.2015.11.004

Shalhoub, S. (2020). Interferon beta-1b for COVID-19. The Lancet, 395 (10238), 1670-1671. doi:https://doi.org/10.1016/S0140-6736(20)31101-6

Sheahan, T. P., Sims, A. C., Leist, S. R., Schafer, A., Won, J., Brown, A. J., . . Baric, R. S. (2020). Comparative therapeutic efficacy of remdesivir and combination lopinavir, ritonavir, and interferon beta against MERS-CoV. Nat Commun, 11 (1), 222. doi:10.1038/s41467-019-13940-6

Sheahan, T. P., Sims, A. C., Leist, S. R., Schäfer, A., Won, J., Brown, A. J., . . . Baric, R. S. (2020). Comparative therapeutic efficacy of remdesivir and combination lopinavir, ritonavir, and interferon beta against MERS-CoV. Nat Commun, 11 (1), 222. doi:10.1038/s41467-019-13940-6

Shi, Y., Wang, Y., Shao, C., Huang, J., Gan, J., Huang, X., . . Melino, G. (2020). COVID-19 infection: the perspectives on immune responses. Cell Death $\&$ Differentiation . doi:10.1038/s41418-020-0530-3

Sica, D. A., Gehr, T. W., \& Ghosh, S. (2005). Clinical pharmacokinetics of losartan. Clin Pharmacokinet, 44 (8), 797-814. doi:10.2165/00003088-200544080-00003

Siddiqi, H. K., \& Mehra, M. R. (2020). COVID-19 illness in native and immunosuppressed states: A clinical\& therapeutic staging proposal.The Journal of Heart and Lung Transplantation, 39 (5), 405-407. doi:10.1016/j.healun.2020.03.012 
Smolen, J. S., Beaulieu, A., Rubbert-Roth, A., Ramos-Remus, C., Rovensky, J., Alecock, E., . . . Alten, R. (2008). Effect of interleukin-6 receptor inhibition with tocilizumab in patients with rheumatoid arthritis (OPTION study): a double-blind, placebo-controlled, randomised trial. Lancet, 371 (9617), 987-997. doi:10.1016/s0140-6736(08)60453-5

Smolen, J. S., Genovese, M. C., Takeuchi, T., Hyslop, D. L., Macias, W. L., Rooney, T., . . Winthrop, K. L. (2018). Safety Profile of Baricitinib in Patients with Active Rheumatoid Arthritis with over 2 Years Median Time in Treatment. J Rheumatol, jrheum.171361. doi:10.3899/jrheum.171361

Spiezia, L., Boscolo, A., Poletto, F., Cerruti, L., Tiberio, I., Campello, E., . . Simioni, P. (2020). COVID19-Related Severe Hypercoagulability in Patients Admitted to Intensive Care Unit for Acute Respiratory Failure. Thromb Haemost (EFirst). doi:10.1055/s-0040-1710018

Spinelli, F. R., Ceccarelli, F., Di Franco, M., \& Conti, F. (2020). To consider or not antimalarials as a prophylactic intervention in the SARS-CoV-2 (Covid-19) pandemic. Annals of the Rheumatic Diseases, 79 (5), 666. doi:10.1136/annrheumdis-2020-217367

Stebbing, J., Phelan, A., Griffin, I., Tucker, C., Oechsle, O., Smith, D., \& Richardson, P. (2020). COVID19: combining antiviral and anti-inflammatory treatments. The Lancet Infectious Diseases, 20 (4), 400-402. doi:https://doi.org/10.1016/S1473-3099(20)30132-8

Su, H., Yang, M., Wan, C., Yi, L.-X., Tang, F., Zhu, H.-Y., . . . Zhang, C. (2020). Renal histopathological analysis of 26 postmortem findings of patients with COVID-19 in China. Kidney International . doi:10.1016/j.kint.2020.04.003

Summers, L. (2020). Why your health may never be the same after Covid-19. Retrieved from

Swedish Orphan Biovitrum Ltd. (2007). SUMMARY OF PRODUCT CHARACTERISTICS - Kineret. In.

Synairgen plc. (2018). IFN- $\beta$ (SNG001) in COPD. Retrieved from https://www.synairgen.com/programmes/ifn-\%CE\%B2-in-copd/

Tanaka, Y., Wada, K., Takahashi, Y., Hagino, O., van Hoogstraten, H., Graham, N. M. H., \& Kameda, H. (2019). Sarilumab plus methotrexate in patients with active rheumatoid arthritis and inadequate response to methotrexate: results of a randomized, placebo-controlled phase III trial in Japan. Arthritis Res Ther, 21 (1), 79. doi:10.1186/s13075-019-1856-4

Tang, W., Gao, Z, Han M, Wang Z, Chen J, Sun W, Wu, Y, Xiao, W, Liu, S, Chen, E, Chen, W, Wang, X, Yang, J, Lin, J, Zhao, Q, Yan, Y, Xie, Z, Li, D, Yang, Y, Liu, L, Qiu, J, Ning, G, Shi, G, Xie, Q. (2020). Hydroxychloroquine in patients with COVID-19: an open-label, randomized, controlled trial. medRxiv . doi:https://doi.org/10.1101/2020.04.10.20060558

Taylor, P. C., Weinblatt, M. E., Burmester, G. R., Rooney, T. P., Witt, S., Walls, C. D., . . . Takeuchi, T. (2019). Cardiovascular Safety During Treatment With Baricitinib in Rheumatoid Arthritis.Arthritis Rheumatol, 71 (7), 1042-1055. doi:10.1002/art.40841

Tchesnokov, E. P., Feng, J. Y., Porter, D. P., \& Gotte, M. (2019). Mechanism of Inhibition of Ebola Virus RNA-Dependent RNA Polymerase by Remdesivir. Viruses, 11 (4). doi:10.3390/v11040326

Thiel, V., \& Weber, F. (2008). Interferon and cytokine responses to SARS-coronavirus infection. Cytokine Growth Factor Rev, 19 (2), 121-132. doi:10.1016/j.cytogfr.2008.01.001

Tignanelli, C. J., Ingraham, N. E., Sparks, M. A., Reilkoff, R., Bezdicek, T., Benson, B., . . . Puskarich, M. A. (2020). Antihypertensive drugs and risk of COVID-19? Lancet Respir Med, 8 (5), e30-e31. doi:10.1016/s2213-2600(20)30153-3

Tirado, S. M. C., \& Yoon, K.-J. (2003). Antibody-Dependent Enhancement of Virus Infection and Disease. Viral Immunology, 16 (1), 69-86. doi:10.1089/088282403763635465 
Torjesen, I. (2020). Covid-19: ibuprofen can be used for symptoms, says UK agency, but reasons for change in advice are unclear. BMJ, $369, \mathrm{~m} 1555$. doi:10.1136/bmj.m1555

Usai, C., Maestro, S., Camps, G., Olague, C., Suarez-Amaran, L., Vales, A., . . . Gonzalez-Aseguinolaza, G. (2020). TNF-alpha inhibition ameliorates HDV-induced liver damage in a mouse model of acute severe infection. JHEP Rep, 2 (3), 100098. doi:10.1016/j.jhepr.2020.100098

Varga, Z., Flammer, A. J., Steiger, P., Haberecker, M., Andermatt, R., Zinkernagel, A. S., . . . Moch, H. (2020). Endothelial cell infection and endotheliitis in COVID-19. Lancet, 395 (10234), 1417-1418. doi:10.1016/s0140-6736(20)30937-5

Vennema, H., De Groot, R., Harbour, D., Dalderup, M., Gruffydd-Jones, T., Horzinek, M., \& Spaan, W. (1990). Early death after feline infectious peritonitis virus challenge due to recombinant vaccinia virus immunization. Journal of virology, 64 (3), 1407-1409.

Villegas, L., McGready, R., Htway, M., Paw, M. K., Pimanpanarak, M., Arunjerdja, R., . . . Nosten, F. (2007). Chloroquine prophylaxis against vivax malaria in pregnancy: a randomized, double-blind, placebocontrolled trial. Trop Med Int Health, 12 (2), 209-218. doi:10.1111/j.1365-3156.2006.01778.x

Vincent, M. J., Bergeron, E., Benjannet, S., Erickson, B. R., Rollin, P. E., Ksiazek, T. G., . . . Nichol, S. T. (2005). Chloroquine is a potent inhibitor of SARS coronavirus infection and spread. Virol J, 2 , 69. doi:10.1186/1743-422X-2-69

Walker, O., Dawodu, A. H., Adeyokunnu, A. A., Salako, L. A., \& Alvan, G. (1983). Plasma chloroquine and desethylchloroquine concentrations in children during and after chloroquine treatment for malaria. $\mathrm{Br}$ J Clin Pharmacol, 16 (6), 701-705. doi:10.1111/j.1365-2125.1983.tb02244.x

Walther, E. U., \& Hohlfeld, R. (1999). Multiple sclerosis. Side effects of interferon beta therapy and their management, 53 (8), 1622-1622. doi:10.1212/wnl.53.8.1622

Warren, T. K., Jordan, R., Lo, M. K., Ray, A. S., Mackman, R. L., Soloveva, V., . . . Bavari, S. (2016). Therapeutic efficacy of the small molecule GS-5734 against Ebola virus in rhesus monkeys. Nature, 531 (7594), 381-385. doi:10.1038/nature17180

Warren, T. K., Jordan, R., Lo, M. K., Ray, A. S., Mackman, R. L., Soloveva, V., . . . Bavari, S. (2016). Therapeutic efficacy of the small molecule GS-5734 against Ebola virus in rhesus monkeys. Nature, 531 (7594), 381-385. doi:10.1038/nature17180

Weber, M. (1997). Clinical safety and tolerability of losartan.Clin Ther, 19 (4), 604-616; discussion 603. doi:10.1016/s0149-2918(97)80086-0

Weinblatt, M. E., Kremer, J., Cush, J., Rigby, W., Teng, L. L., Devenport, J., . . . Genovese, M. C. (2013). Tocilizumab as monotherapy or in combination with nonbiologic disease-modifying antirheumatic drugs: twenty-four-week results of an open-label, clinical practice study. Arthritis Care Res (Hoboken), 65 (3), 362-371. doi:10.1002/acr.21847

World Health Organisation. (2018). Ad-hoc Expert Consultation on clinical trials for Ebola Therapeutics. Retrieved from https://www.who.int/ebola/drc-2018/summaries-of-evidence-experimentaltherapeutics.pdf?ua=1

World Health Organisation. (2020a). Coronavirus disease 2019 (COVID-19)

Situation Report - 59. In.

World Health Organisation. (2020b). DRAFT landscape of COVID-19 candidate vaccines - 27 May 2020. In. Available from: https://www.who.int/who-documents-detail/draft-landscape-of-covid-19-candidatevaccines: World Health Organization. 
Wu, D., Wu, T., Liu, Q., \& Yang, Z. (2020). The SARS-CoV-2 outbreak: what we know. Int J Infect Dis . doi:10.1016/j.ijid.2020.03.004

Wu, X., Li, Y., Peng, K., \& Zhou, H. (2014). HIV protease inhibitors in gut barrier dysfunction and liver injury. Curr Opin Pharmacol, 19 , 61-66. doi:10.1016/j.coph.2014.07.008

Yam, C., Fok, A., McLean, C., Butler, E., \& Kempster, P. (2018). 035 Interferon beta induced thrombotic microangiopathy in multiple sclerosis: a clinical-pathological report. Journal of Neurology, Neurosurgery Éamp; Psychiatry, 89 (6), A15-A15. doi:10.1136/jnnp-2018-ANZAN.34

Yang, B.-B., Baughman, S., \& Sullivan, J. T. (2003). Pharmacokinetics of anakinra in subjects with different levels of renal function. Clinical Pharmacology \&3 Therapeutics, 74 (1), 85-94. doi:10.1016/s00099236(03)00094-8

Yang, L. P. H., \& Keating, G. M. (2012). Ruxolitinib. Drugs, 72 (16), 2117-2127. doi:10.2165/11209340000000000-00000

Yang, X., Yu, Y., Xu, J., Shu, H., Xia, J., Liu, H., . . . Shang, Y. (2020). Clinical course and outcomes of critically ill patients with SARS-CoV-2 pneumonia in Wuhan, China: a single-centered, retrospective, observational study. Lancet Respir Med . doi:10.1016/s2213-2600(20)30079-5

Yao, X., Ye, F., Zhang, M., Cui, C., Huang, B., Niu, P., . . . Liu, D. (2020). In Vitro Antiviral Activity and Projection of Optimized Dosing Design of Hydroxychloroquine for the Treatment of Severe Acute Respiratory Syndrome Coronavirus 2 (SARS-CoV-2). Clin Infect Dis . doi:10.1093/cid/ciaa237

Zhang, C., Shi, L., \& Wang, F. S. (2020). Liver injury in COVID-19: management and challenges. Lancet Gastroenterol Hepatol, 5 (5), 428-430. doi:10.1016/s2468-1253(20)30057-1

Zhang, L., Zhang, Y., \& Huang, S. M. (2009). Scientific and regulatory perspectives on metabolizing enzymetransporter interplay and its role in drug interactions: challenges in predicting drug interactions. Mol Pharm, 6 (6), 1766-1774. doi:10.1021/mp900132e

Zhao, Y., Zhao, Z., Wang, Y., Zhou, Y., Ma, Y., \& Zuo, W. (2020). Single-cell RNA expression profiling of ACE2, the putative receptor of Wuhan 2019-nCov. bioRxiv , 2020.2001.2026.919985. doi: $10.1101 / 2020.01 .26 .919985$

Zheng, Y. Y., Ma, Y. T., Zhang, J. Y., \& Xie, X. (2020). COVID-19 and the cardiovascular system. Nat Rev Cardiol, 17 (5), 259-260. doi:10.1038/s41569-020-0360-5

\section{Hosted file}

Table 1.docx available at https://authorea.com/users/333124/articles/459391-safetyperspectives-on-presently-considered-drugs-for-the-treatment-of-covid-19 


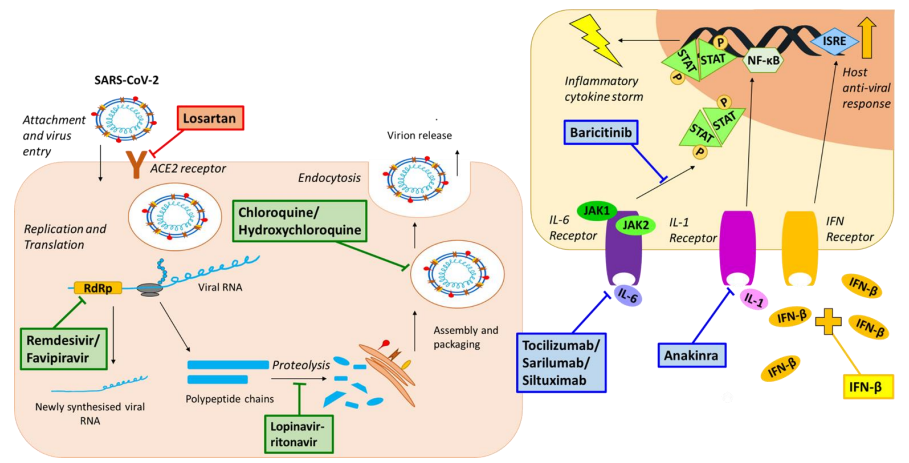

